\title{
TAXES AND MARRIAGE: A TWO-SIDED SEARCH ANALYSIS*
}

\author{
By Hector Chade and Gustavo Ventura ${ }^{1}$ \\ Arizona State University, U.S.A., and \\ Pennsylvania State University, U.S.A.
}

\begin{abstract}
This article analyzes the effects of differential tax treatment of married and single individuals in the United States on marriage formation and composition, divorce, and labor supply. We develop a marriage-market model with search frictions and heterogeneous agents that is sufficiently rich to capture key elements of the problem under consideration. We then calibrate the model and use it to evaluate the quantitative effects of several tax reforms aimed at making the tax law neutral with respect to marital status. We find that these reforms (i) systematically increase the labor supply of married females, with changes ranging from 0.3 to 10.1 percent; (ii) have substantial effects on the correlation of spouses' incomes, which changes from 0.2 to values between 0.185 and 0.334 ; (iii) can lead to either an increase or decrease in the fraction of people married, with changes that range from -0.6 to 2.4 percent.
\end{abstract}

\section{INTRODUCTION}

Since Becker's $(1973,1974)$ seminal papers on marriage, researchers from different fields have been paying close attention to the effects of economic factors on the formation, composition, and dissolution of households. Among these factors, one that has received considerable recent attention in U.S. policy circles is the differential tax treatment of married and single individuals. ${ }^{2}$ Lack of marriage neutrality in the tax system may alter the combined tax liabilities of two single individuals after they marry, leading to a tax "penalty" (higher tax liability) or a tax "bonus" (lower tax liability). Perhaps more importantly, this lack of neutrality can generate significant variations in the marginal tax rates that individuals face after they change marital status.

* Manuscript received August 1999; revised September 2001.

${ }^{1}$ We have benefited from detailed comments by David Andolfatto, Andrés Erosa, Lutz Hendricks, Ig Horstmann, John Knowles, Peter Morgan, Shanon Seitz, Alan Slivinski, Jeffrey Smith, Marcelo Veracierto, Randall Wright, and by seminar participants at Centro de Investigación Económica (ITAM), Western Ontario, 2000 SED Meetings, Rochester, Georgetown, Alberta, UQAM, Federal Reserve Bank of Chicago, Federal Reserve Bank of Atlanta, Pennsylvania State University, 2001 CEA Meetings, and 2001 Latin American Econometric Society Meetings. We are also grateful to an associate editor and three anonymous referees for their helpful comments and suggestions. E-mail: hector.chade@asu.edu and cjv10@psu.edu.

${ }^{2}$ In popular discussions, this is commonly referred to as the "marriage tax" or the "marriage penalty." 
Differential tax treatment of married and single individuals is a fundamental feature of the U.S. tax system, and derives from a host of provisions embedded in the federal law. In addition to the general rule that for married individuals the unit subject to taxation is the income of the couple instead of the incomes of the two individuals considered separately, there are two provisions that contribute substantially to this issue. First, separate tax schedules exist for single individuals and married couples. Although the magnitude of marginal tax rates is the same under both schedules, the width of tax brackets for married couples is less than twice the width for single individuals. Second, the standard deduction for married couples is less than twice the standard deduction for single people. ${ }^{3}$

It is natural to surmise that lack of neutrality in the tax law toward marriage can have effects on marriage and divorce decisions, on the composition of the marriage pool (who marries whom), and on the labor-supply decisions of single and married individuals.

This article studies the effects that differential tax treatment of married and single individuals has on these variables. We first develop a marriage-market model with search frictions and heterogeneous agents that is sufficiently rich to capture some of the key elements of the problem under consideration. We then use the model to evaluate quantitatively the effects of several tax reforms that are aimed at making the tax law neutral with respect to marital status.

The essential features of our model can be summarized as follows. The economy is comprised of a large number of individuals, men and women, who are endowed with a labor productivity type that evolves stochastically over time, and who face different tax schedules depending upon their marital status. In each period, a single individual has to decide how many hours to work given his or her productivity and the tax system; moreover, singles randomly meet pairwise with potential marriage partners. In a given meeting, after observing each other's productivities and an initial estimate of the "quality" of the prospective match, both parties decide whether to marry or not. If either of them rejects the prospect of forming a match with the current partner, both individuals must wait an entire period before meeting another potential mate. If they get married, then in each period they use a simple cooperative model to decide how many hours each spouse will work, given their current labor productivities, the current quality of the match, and the tax schedule they face. Also, at the beginning of each period, the spouses decide if they want to continue being married after observing the new attributes of the couple. If any of the spouses decides to end the relationship, they both remain single for an entire period before meeting a new prospective mate. In equilibrium, the marital and labor decisions of all agents determine the number and the composition of the pools of married and single individuals.

We calibrate our model to match a number of empirical observations regarding labor and marriage markets in the United States, and we solve it numerically. We

\footnotetext{
${ }^{3}$ Although there are many other provisions in the tax law that contribute to the problem, it has long been recognized that the two features described above can by themselves affect individual behavior along several dimensions. See General Accounting Office (1996) for a detailed description of all the features of the tax law that lead to marriage penalties and bonuses.
} 
then conduct revenue-neutral experiments in which we replace our approximation of the current tax system with three alternative schemes, and in each case we compute the new steady state of the model and compare it with the benchmark case. The first experiment, labeled partial tax reform, sets the standard deduction and the size of the tax brackets for married individuals equal to twice the size of those applied to single people. In the second reform, we make the individual the unit subject to taxation: that is, all individuals, married or single, face the tax schedule that is currently in place for singles; we call this the fundamental tax reform. Finally, we study two drastic related cases that we label flat and negative income tax reforms, respectively. In both cases, marginal tax rates are the same for everyone and the unit subject to taxation is the individual; however, only in the negative income tax case is the system progressive in the sense of having increasing average tax rates.

Our quantitative experiments reveal that the partial or total elimination of differential tax treatment toward married and single individuals has important longrun effects on the formation and dissolution of marriages, assortative mating, and, more importantly, on the labor supply of married females. The main findings can be summarized as follows:

- Marriage formation: We find that the number of married individuals can either increase or decrease depending on the type of reform implemented, with changes ranging from -0.6 to 2.4 percent. In particular, it is interesting to note that two reforms that fully achieve marriage neutrality, namely the fundamental and flat income tax reforms, have opposite effects on marriage formation and dissolution.

- Assortative mating: The correlation of spouses' wages under different reforms changes from 0.653 in the benchmark case to values between 0.640 and 0.695 . If we instead measure the degree of assortative mating by the correlation of spouses' incomes (which includes labor-supply decisions), this variable changes from 0.20 in the benchmark case to values between 0.185 and 0.334. In several instances, we find that the measures of assortative mating move in different directions.

- Labor supply: A prominent finding of our analysis is that implementing marriage-tax neutrality can have significant quantitative effects on the labor supply of married females. For example, the fundamental reform, which maintains the type of progressivity embodied in the current law and is, therefore, quite relevant for policy considerations, generates an increase in the mean number of hours worked by married females of about 2.9 percent. Furthermore, this increase becomes more important as the joint income of a married couple increases. It is worth noting that these effects are due exclusively to the replacement of the current tax system by an individualbased system.

We provide intuitive explanations for all our results that rely on the interplay of forces present in the model.

Throughout the article, we emphasize the importance of analyzing the issues described above in a general equilibrium framework where labor and marital 
decisions are intertwined, and where agents are aware of the two-sided search nature of the environment in which they interact. In order to develop this point further, we conduct experiments in which the effects of the reforms are assessed using "partialequilibrium" versions of the model in which some features of our framework are suppressed. For example, in one of the experiments, we study the effects of the reforms when agents do not take into account the "two-sided" search aspects of the model; that is, when they assume that the reforms do not affect the meeting probabilities and the strategies used by other agents. We find that these "partialequilibrium" analyses lead to substantially different results, affecting not only the magnitude but also the direction of changes.

This is the first article that addresses the role of the differential tax treatment of married and single individuals in an equilibrium-search model. As such, it is related to the recent literature on matching models that includes Burdett and Coles (1997), Burdett and Wright (1998), Chade (2001), Morgan (1996), Lu and McAffee (1996), Bloch and Ryder (2000), Shimer and Smith (2000), and Smith (1997). It is also closely connected to some applied general equilibrium studies of marriage and family formation. Examples are Aiyagari et al. (2000), who study the effects of welfare policies and their connections with marriage markets; Greenwood et al. (2000), who investigate the role of family formation and fertility choice upon the distribution of income; and Regalia and Rios-Rull (1999), who assess the role played by different factors on the twin observations of stability of fertility and increase in single motherhood. Our work is also related to a number of empirical articles that have estimated the effects that income taxation has on marriage and divorce in the United States (e.g., Alm and Whittington, 1995a, 1995b, 1997; Whittington and Alm, 1996; Sjoquist and Walker, 1995). Our article differs from this last group, as we cast the issues in the context of an equilibrium-search model of marriage formation and dissolution. As a result, we provide a suitable environment to assess quantitatively the effects of various potential tax reforms.

The article is organized as follows. Section 2 discusses the tax treatment of married and single individuals in the United States and its implications at an informal level. The model is described in Section 3. Section 4 discusses the calibration procedure and Section 5 reports the quantitative properties of the benchmark economy. The main findings of the article are presented in Section 6, where the effects of the reforms are evaluated and explained. Section 7 analyzes the effects of reforms when some of the general equilibrium features of the model are omitted. Section 8 concludes. In the Appendix, we provide an alternative interpretation of the steadystate conditions of the model, and we describe the computational algorithm used in the quantitative exercises.

\section{TAX TREATMENT OF MARRIED AND SINGLE INDIVIDUALS IN THE UNITED STATES}

In order to illustrate some of the key implications of current tax rules, consider two hypothetical cases under the 1994 U.S. tax schedule (see Table 1). In the first case, individuals $\mathrm{A}$ and $\mathrm{B}$ have equal incomes when single, namely $\$ 30,000$. As single individuals, each one has a taxable income equal to $\$ 30,000-\$ 3800-\$ 2450=$ $\$ 23,750$, and pays the amount $0.15 \times \$ 22,750+0.28 \times(\$ 23,750-\$ 22,750)=\$ 3,692.5$ 
TABLE 1

INCOME TAX SCHEDULE (I994) (LOWEST TAXABLE INCOME FOR TAX RATES)

\begin{tabular}{lccc}
\hline Marginal Tax Rate & Joint $(1)$ & Single $(2)$ & $(1) /(2)$ \\
\hline 0.15 & 0 & 0 & - \\
0.28 & 38,000 & 22,750 & 1.67 \\
0.31 & 91,850 & 55,100 & 1.67 \\
0.36 & 140,000 & 115,000 & 1.22 \\
0.396 & 250,000 & 250,000 & 1.0 \\
Personal ex. & $2 \times 2450$ & 2450 & 2.0 \\
St. deduction & 6350 & 3800 & 1.67 \\
\hline
\end{tabular}

in income taxes. If $\mathrm{A}$ and $\mathrm{B}$ decide to get married, assuming their incomes do not vary, their taxable income as a couple is $\$ 60,000-\$ 6350-2 \times \$ 2,450=\$ 48,750$ and their income-tax payment is $0.15 \times \$ 38,000+0.28 \times(\$ 48,750-\$ 38,000)=\$ 8710$. Therefore, the change in marital status leads to a tax penalty equal to 1325 .

Marriage does not always lead to an increase in the tax burden; depending on the incomes of the spouses, marriage can instead yield a tax bonus. As an illustration, suppose that A and B earn $\$ 20,000$ and $\$ 80,000$, respectively. As single individuals, A would pay $\$ 2062.5$ in income taxes under a marginal tax rate of 0.15 , whereas B would pay $0.15 \times \$ 22,750+0.28 \times(\$ 55,100-\$ 22,750)+0.31 \times(\$ 73,750-\$ 55,100)=$ $\$ 18,252$. If $\mathrm{A}$ and $\mathrm{B}$ get married and their individual incomes do not change, they would pay as a couple $\$ 19,910$ in income taxes and face a common marginal tax rate of 28 percent; thus, they enjoy a tax bonus equal to $\$ 404.5(\$ 19,910-\$ 18,252-$ $\$ 2062.5=-\$ 404.5)$. The reason is that, given that the couple is the unit subject to taxation, a larger fraction of the inframarginal income of the spouse with the highest income is taxed at lower rates.

The above examples illustrate the well-known fact that both tax penalties and bonuses coexist under the current law, which tends to penalize couples with spouses whose individual incomes are similar, and benefits those whose incomes are farther apart.

We can use these examples to cast some light on the potential effects of tax reforms. Notice that it is not clear how a drastic reform that eliminates both penalties and bonuses may affect marriage formation and dissolution in the aggregate, since its impact varies according to the characteristics of the individuals. This makes the effect of such a reform on assortative mating (who marries whom) an interesting issue to investigate. Also, a reform aimed at eliminating marriage penalties and bonuses can have nontrivial effects on labor supply, even if the potential distortions associated with increasing marginal tax rates are not eliminated by the reform. This can be easily illustrated using the second example described above. If a married A wanted to increase his or her income by working more, he or she would face the marginal tax rate of the couple (28 percent). Instead, under a system in which each individual faces the tax schedule for single people no matter what his or her marital status is (i.e., the unit subject to taxation is the individual), the marginal tax rate faced by A would be just 15 percent. Finally, notice that a simple reform that makes the amount of the standard deduction and the sizes of the brackets for married 
couples equal to twice the amount and sizes applied to single individuals does not achieve marriage neutrality. As an illustration, such a reform would eliminate the tax penalty in the first example but increase the tax bonus in the second example; the couple's taxable income would now amount to $\$ 87,500$, and their tax payments would be reduced to $\$ 18,585$. As a result, the marriage bonus would be equal to $\$ 1729.5$, which is substantially larger than $\$ 404.5$. Furthermore, the marginal tax rate of the "second earner" (individual A) still varies with the change in marital status: It is now 28 percent instead of 15 percent.

\section{THE MODEL}

In this section, we describe the framework that constitutes the basis for the computational exercises conducted in the rest of the article. We first provide an overview of the main features of the model; next, the marriage market and household decisions faced by the agents are specified in detail. Then, we describe how the equilibrium-meeting probabilities are calculated using the "demographic" characteristics of the model and agents' decision rules. Finally, we formulate a suitable equilibrium concept for this framework.

\subsection{The Environment. The main characteristics of the model are:}

Time: The horizon is infinite and time is discrete; that is, $t=0,1,2, \ldots$.

Agents: There are two populations of agents, one containing a continuum of males and the other a continuum of females. The total mass of agents in each population is normalized to one.

Heterogeneity: Males and females are endowed with one unit of (nonsleeping) time per period and with a labor productivity trait (type), whose evolution is driven by a Markov process with a stationary transition function. The labor productivity type of a female in any given period is denoted by $x \in X$, where $X \subset \mathbb{R}_{+}$is a finite set; $x$ evolves according to $q\left(x^{\prime} \mid x\right)$. In steady state, which is the focus of our equilibrium analysis, the distribution of female types in every period is given by $\lambda: X \rightarrow[0,1]$, with $\lambda(x)>0$ for all $x$ and $\sum_{x} \lambda(x)=1$; this distribution is also the unique stationary distribution of $q(\cdot \mid \cdot){ }^{4}$ Similarly, the labor productivity of a male in any given period is denoted by $y \in Y, Y \subset \mathbb{R}_{+}$finite; $y$ fluctuates according to $p\left(y^{\prime} \mid y\right)$, whose unique stationary distribution is $\mu: Y \rightarrow[0,1]$, with $\mu(y)>0$ for all $y$ and $\sum_{y} \mu(y)=1$. In each period, agents face a constant probability of death; it is denoted by $\delta_{F}$ for females and by $\delta_{M}$ for males.

\footnotetext{
${ }^{4}$ There are two ways to justify this construction formally: (i) In any given period, each female with type $x$ (there is a continuum of them) independently draws a new type from $q(\cdot \mid x)$; using Proposition 2 in Judd (1985), one can assume that the realized distribution of draws will be $q(\cdot \mid x)$. After doing this for every $x$, the number of females with type $x^{\prime}$ is $\sum_{x} q\left(x^{\prime} \mid x\right) \lambda(x)=\lambda\left(x^{\prime}\right)$; a similar analysis holds for males. (ii) One could abandon the assumption that women draw their new types independently of each other, and simply assume that these draws are independent from the men's. Pairwise meetings between men and women and perfect observation of their current types imply that individuals cannot profit from the knowledge that the draws can be correlated. In this case, Proposition 2 in Feldman and Gilles (1985) yields the desired construction.
} 
Match formation: In every period, single men and women randomly meet in pairs; in equilibrium, the probability that a male meets a female with current type $x \in X$ is $\psi(x)$, whereas the probability that a female meets a male with current type $y \in Y$ is $\phi(y)$. At a meeting, individuals observe each other's current productivity types and also the initial quality of the match $\theta$ drawn from the distribution $\pi: \Theta \rightarrow[0,1]$, with $\Theta \in \mathbb{R}$ finite, $\pi(\theta)>0$, and $\sum_{\theta} \pi(\theta)=1$. After that, they simultaneously announce Accept or Reject. If both accept, they marry; otherwise, they return to the pool of singles and wait to be matched anew in the next period. Match quality evolves over time according to a Markov process with transition function $r\left(\theta^{\prime} \mid \theta\right)$, whose unique stationary distribution is also $\pi(\cdot)$.

Match dissolution: At the beginning of each period, if both spouses are alive, then after observing their current types and match quality they announce whether they want to Continue and stay married in the current period, or Divorce now and go back to the marriage market in the next period. They remain together if and only if both want to continue; otherwise, the match is dissolved. If a spouse dies, then it is assumed that the survivor disappears from the model and remains single until he or she dies.

Household decision making: A single agent allocates part of his or her time to work $(l)$ and the rest to leisure activities $(1-l)$; the time spent working, the productivity of the agent, and income taxes determine the amount of consumption (c) the agent enjoys. For married agents, consumption in each period is determined by the amount of time each spouse spends at work, as well as their productivities, income taxes, and the quality of the match. Within a household, the labor supply of each spouse in each period is determined by the solution of a static planning problem that is described below.

Taxation: The income of a household in each period is given by the sum of the earnings of the members of the household, which is in turn determined by their labor supply and current productivities. Part of this income is paid to the government as taxes, in a way to be specified below. We assume that tax revenues are consumed by the government and not returned to the individuals.

Payoffs: All agents have the same per-period utility function $U(c, 1-l)$, which is continuous, strictly increasing in $c$ and strictly decreasing in $l$. In equilibrium, the level of utility an individual enjoys in each period is determined by his or her consumption and leisure, which are decided within the household and depend on current types, marital status, quality of the match (if married), as well as taxes imposed. We shall denote by $g^{s}(y)$ and $g^{w}(y)$ the indirect per-period utility function of a single male and a widowed male, respectively, with current type $y ; f^{s}(x)$ and $f^{w}(x)$ are defined analogously. Similarly, $g^{m}(x, y, \theta)$ is the indirect per-period utility function of a married male with current type $y$, current spouse type $x$, and current match quality $\theta ; f^{m}(x, y, \theta)$ has an analogous interpretation. Agents discount the future at a common discount factor $0<\beta<1$.

Flows in and out of the market: In each period, agents who marry leave the marriage market, whereas married couples who decided to split in the previous period flow into the pool of singles. Also, it is assumed that agents who die or become widowed (recall that they also disappear from the model) are instantly replaced by clones that immediately enter the marriage market. This ensures that the sizes of the populations of men and women remain constant over time. 
In equilibrium, the flows in and out of the pool of singles (or in and out of the marriage stock) are equal in every period.

3.2. Marriage Market Decisions. Let $\psi(\cdot)$ and $\phi(\cdot)$ be the meeting probabilities in the marriage market. The following indicator functions will be used to denote agents' marital decisions: $I_{M}^{s}(\cdot, y, \cdot): X \times \Theta \rightarrow\{0,1\}$ is the decision function of a single male with current type $y$; it assumes a value of 1 if he announces Accept and 0 if he announces Reject. For a married male with current type $y$, the indicator function that summarizes his strategy is given by $I_{M}^{m}(\cdot, y, \cdot): X \times \Theta \rightarrow\{0,1\}$, where a value of 1 indicates Continue and a value of 0 means Divorce. The decision functions of females, $I_{F}^{s}(x, \cdot, \cdot)$ and $I_{F}^{m}(x, \cdot, \cdot)$, are defined in a similar way.

Consider a married male with current type $y$ in state $(x, y, \theta)$ (i.e., his spouse has current type $x$ and the current quality of the match is $\theta$ ). The recursive formulation of his problem is

$$
\begin{aligned}
v^{m}(x, y, \theta)= & g^{m}(x, y, \theta)+\beta\left(1-\delta_{M}\right)\left(1-\delta_{F}\right) \sum_{y^{\prime}} \sum_{x^{\prime}} \sum_{\theta^{\prime}} p\left(y^{\prime} \mid y\right) q\left(x^{\prime} \mid x\right) \\
& \times r\left(\theta^{\prime} \mid \theta\right)\left[v^{s}\left(y^{\prime}\right)\left(1-I_{F}^{m}\left(x^{\prime}, y^{\prime}, \theta^{\prime}\right)\right)+\max \left\{v^{m}\left(x^{\prime}, y^{\prime}, \theta^{\prime}\right), v^{s}\left(y^{\prime}\right)\right\}\right. \\
& \left.\times I_{F}^{m}\left(x^{\prime}, y^{\prime}, \theta^{\prime}\right)\right]+\beta\left(1-\delta_{M}\right) \delta_{F} \sum_{y^{\prime}} p\left(y^{\prime} \mid y\right) v^{w}\left(y^{\prime}\right)
\end{aligned}
$$

where $v^{s}(y)$ and $v^{w}(y)$ are the values of being single and widowed, respectively, when the current type is $y$ and before the current consumption decision is made. The righthand side of the equation is explained as follows. The first term reflects his current (indirect) utility as a married agent, whereas the second and third terms summarize his discounted expected continuation utility under an optimal strategy. Next period, if both spouses are alive, then their types and the quality of the match are updated; in the event that his spouse wants a divorce, he has no decision to make and he is forced to go back to the pool of singles. Otherwise, he has to decide whether he wants to continue being married or not: The payoffs associated with each alternative are described by the terms inside the max operator. Finally, if his spouse dies in the next period, he lives from this point onward as a widower; this prospect has an expected discounted payoff given by the last term of (1).

The Bellman equation for a single male with current type $y$ is given by

$$
\begin{aligned}
v^{s}(y) & =g^{s}(y)+\beta\left(1-\delta_{M}\right) \sum_{y^{\prime}} \sum_{x^{\prime}} \sum_{\theta^{\prime}} p\left(y^{\prime} \mid y\right) \psi\left(x^{\prime}\right) \pi\left(\theta^{\prime}\right) \\
& \times\left[v^{s}\left(y^{\prime}\right)\left(1-I_{F}^{s}\left(x^{\prime}, y^{\prime}, \theta^{\prime}\right)\right)+\max \left\{v^{m}\left(x^{\prime}, y^{\prime}, \theta^{\prime}\right), v^{s}\left(y^{\prime}\right)\right\} I_{F}^{s}\left(x^{\prime}, y^{\prime}, \theta^{\prime}\right)\right]
\end{aligned}
$$

The first term on the right-hand side is the current utility he enjoys as a single agent, whereas the second term is the expected continuation value under an optimal strategy. If he is alive in the next period, then his type will change, he will meet a single female, and observe her type and the initial quality of the match. In the event that she rejects him, his expected discounted payoff is his value as a single person. If she accepts him, then he has to decide between Accept and get married, with expected discounted payoff given by the first term inside the max operator, or Reject and continue living as a single agent. 
As we pointed out before, widows and widowers do not go back to the marriage market. We assume that the expected discounted utility that a widowed male with current type $y$ enjoys is equal to his "autarkic" payoff. Formally,

$$
v^{w}(y)=g^{w}(y)+\beta\left(1-\delta_{M}\right) \sum_{y^{\prime}} p\left(y^{\prime} \mid y\right) v^{w}\left(y^{\prime}\right)
$$

where the first term is his current utility and the second term is his discounted expected payoff from the next period onward.

It is evident from (1) and (2) that the optimal decision functions for single and married males with current type $y$ are, respectively,

$$
\begin{aligned}
& I_{M}^{s}(x, y, \theta)= \begin{cases}1 & \text { if } v^{m}(x, y, \theta) \geq v^{s}(y) \\
0 & \text { otherwise }\end{cases} \\
& I_{M}^{m}(x, y, \theta)= \begin{cases}1 & \text { if } v^{m}(x, y, \theta) \geq v^{s}(y) \\
0 & \text { otherwise }\end{cases}
\end{aligned}
$$

Notice that a single indicator function characterizes the optimal strategy of a male (female); for, given any $(x, y, \theta)$,

$$
I_{M}^{s}(x, y, \theta)=I_{M}^{m}(x, y, \theta)
$$

A similar analysis holds for females whose current type is $x$. The corresponding Bellman equations and optimal strategies are, respectively,

$$
\begin{aligned}
z^{m}(x, y, \theta)= & f^{m}(x, y, \theta)+\beta\left(1-\delta_{F}\right)\left(1-\delta_{M}\right) \sum_{y^{\prime}} \sum_{x^{\prime}} \sum_{\theta^{\prime}} p\left(y^{\prime} \mid y\right) q\left(x^{\prime} \mid x\right) \\
& \times r\left(\theta^{\prime} \mid \theta\right)\left[z^{s}\left(x^{\prime}\right)\left(1-I_{M}^{m}\left(x^{\prime}, y^{\prime}, \theta^{\prime}\right)\right)+\max \left\{z^{m}\left(x^{\prime}, y^{\prime}, \theta^{\prime}\right), z^{s}\left(x^{\prime}\right)\right\}\right. \\
& \left.\times I_{M}^{m}\left(x^{\prime}, y^{\prime}, \theta^{\prime}\right)\right]+\beta\left(1-\delta_{F}\right) \sum_{x^{\prime}} q\left(x^{\prime} \mid x\right) z^{w}\left(x^{\prime}\right) \\
z^{s}(x)=f^{s}(x) & +\beta\left(1-\delta_{F}\right) \sum_{x^{\prime}} \sum_{y^{\prime}} \sum_{\theta^{\prime}} q\left(x^{\prime} \mid x\right) \phi\left(y^{\prime}\right) \pi\left(\theta^{\prime}\right) \\
& \times\left[z^{s}\left(x^{\prime}\right)\left(1-I_{M}^{s}\left(x^{\prime}, y^{\prime}, \theta^{\prime}\right)\right)+\max \left\{z^{m}\left(x^{\prime}, y^{\prime}, \theta^{\prime}\right), z^{s}\left(x^{\prime}\right)\right\} I_{M}^{s}\left(x^{\prime}, y^{\prime}, \theta^{\prime}\right)\right]
\end{aligned}
$$

$$
\begin{gathered}
z^{w}(x)=f^{w}(x)+\beta\left(1-\delta_{F}\right) \sum_{x^{\prime}} q\left(x^{\prime} \mid x\right) z^{w}\left(x^{\prime}\right) \\
I_{F}^{s}(x, y, \theta)= \begin{cases}1 & \text { if } z^{m}(x, y, \theta) \geq z^{s}(x) \\
0 & \text { otherwise }\end{cases} \\
I_{F}^{m}(x, y, \theta)= \begin{cases}1 & \text { if } z^{m}(x, y, \theta) \geq z^{s}(x) \\
0 & \text { otherwise }\end{cases}
\end{gathered}
$$

3.3. Households. We now specify how households determine the amount of labor supplied by each member and, consequently, the quantity of goods they consume. Agents pay taxes contingent on their income and marital status. Let $T^{s}\left(y l_{M}^{s}\right)$ and $T^{s}\left(x l_{F}^{s}\right)$ denote the tax liabilities of single males and single females, respectively; 
for example, $T^{s}\left(y l_{M}^{s}\right)$ is the amount of income tax paid by a single male with current type $y$ who works a fraction $l_{M}^{s}$ of his time. Similarly, $T^{m}\left(y l_{M}^{m}, x l_{F}^{m}\right)$ denotes the tax liability of a married couple. A tax system is defined as a pair of functions $\left(T^{s}, T^{m}\right)$.

The consumption-leisure problem of a single male with current type $y$ is

$$
\max _{c, l_{M}^{s}} U\left(c, 1-l_{M}^{s}\right)
$$

subject to

$$
c=y l_{M}^{s}-T^{s}\left(y l_{M}^{s}\right) \quad 0 \leq l_{M}^{s} \leq 1
$$

The problem of a single female with type $x$ is analogous. We denote the optimal solutions and value of these problems by $l_{M}^{s}(y), g^{s}(y)$, and $l_{F}^{s}(x), f^{s}(x)$, for males and females, respectively.

Consider now a married couple indexed by $(x, y, \theta)$. We assume that labor supply decisions within the household are made in a cooperative way by solving a simple static planning problem with equal weights. Formally, the couple solves

$$
\max _{c, l_{M}^{m}, l_{F}^{m}} U\left(c, 1-l_{M}^{m}\right)+U\left(c, 1-l_{F}^{m}\right)
$$

subject to

$$
c=(1-\theta)\left[y l_{M}^{m}+x l_{F}^{m}-T^{m}\left(y l_{M}^{m}, x l_{F}^{m}\right)\right] \quad 0 \leq l_{M}^{m} \leq 1 \quad 0 \leq l_{F}^{m} \leq 1
$$

The solution to this problem gives the optimal labor choices for the couple, denoted by $l_{M}^{m}(x, y, \theta)$ and $l_{F}^{m}(x, y, \theta)$. After substituting the solution in $U(\cdot, \cdot)$, we obtain the indirect utility functions $g^{m}(x, y, \theta)$ and $f^{m}(x, y, \theta)$. Notice that we are assuming that consumption in the household is a public good, and the quality of the match affects its quantity multiplicatively. In other words, the match quality shock is a productivity shock to the joint (after tax) output of the married couple. ${ }^{5}$

We now determine the autarkic payoff of widows and widowers. We assume that survivors are exempted from income taxes. Thus, a widowed man with type $y$ solves

$$
\max _{c, l_{M}^{w}} U\left(c, 1-l_{M}^{w}\right)
$$

subject to

$$
c=y l_{M}^{w} \quad 0 \leq l_{M}^{w} \leq 1
$$

The problem of a female survivor with type $x$ is analogous. The optimal solutions and values are $l_{M}^{w}(y), g^{w}(y)$, and $l_{F}^{w}(x), f^{w}(x)$, respectively. ${ }^{6}$

\footnotetext{
${ }^{5}$ This is not the only possible interpretation of $\theta$ : for instance, when the utility function is homogeneous in consumption, it is possible to interpret the term $1-\theta$ as a preference shock in the married state.

${ }^{6}$ The assumptions that (i) widowed people do not go back to the marriage market and that (ii) they do not pay taxes are made to simplify the presentation of the model and the statement of the equilibrium conditions. The quantitative findings do not change significantly when either or both of these assumptions are relaxed.
} 
3.4. Remarks. Our description of married households shares with Aiyagari et al. (2000) and others the notion that a household's disposable income is transformed into a single consumption good that has public-good features. Fluctuations in the match quality variable only affect the fraction of the household income that is available for joint consumption. Therefore, a married household can be viewed as a partnership for the production of public goods. This is the key reason that explains why individuals choose to marry in our model.

Regarding the household planning problem, our choice was guided by computational tractability and equilibrium-selection problems. An alternative would be to use the Nash bargaining solution, taking into account the agents' continuation values and using the discounted payoff of being single as the threat point. The problem with this alternative is that it cannot be computed in a separate way from (1)-(6), and this makes the computation of the model a daunting task. Another choice would be to assume that spouses decide their labor hours in each period in a noncooperative way, taking into account the "state of the couple" (types and match quality), as in Aiyagari et al. (2000); however, the existence of progressive taxes can lead to multiple equilibria whose characteristics depend on spouses' types and the quality of the match, rendering the equilibriumselection problem nontrivial. ${ }^{7}$ Despite its limitations, our modeling of households captures the plausible feature that, within a household, utility is transferable, albeit not perfectly. Moreover, as we demonstrate below, the implied laborsupply behavior of married men and women is consistent with key features of the data.

3.5. Equilibrium Meeting Probabilities. Consider a snapshot of the entire market in steady state. At any point in time, the number of females whose current type is $x \in X, \lambda(x)$, consists of those who are single $u_{F}(x)$, and those who are married, $v_{F}(x)$; that is, $\lambda(x)=u_{F}(x)+v_{F}(x)$ for all $x \in X$. Similarly, $\mu(y)=$ $u_{M}(y)+v_{M}(y)$ for all $y \in Y$. Therefore, the equilibrium meeting probabilities are given by

$$
\begin{aligned}
& \psi(x)=\frac{u_{F}(x)}{\sum_{x} u_{F}(x)} \\
& \phi(y)=\frac{u_{M}(y)}{\sum_{y} u_{M}(y)}
\end{aligned}
$$

for all $x \in X$ and $y \in Y$.

At any point in time, the number of couples indexed by $(x, y, \theta)$ that are married is denoted by $\mathcal{M}(x, y, \theta)$; obviously, if we knew this quantity for every $(x, y, \theta)$, we could obtain $u_{F}(\cdot)$ and $u_{M}(\cdot)$ as follows:

\footnotetext{
${ }^{7}$ Notice also that, unlike this case, our approach implies that household decisions are efficient in a static sense.
} 


$$
\begin{aligned}
& u_{F}(x)=\lambda(x)-\sum_{y} \sum_{\theta} \mathcal{M}(x, y, \theta) \\
& u_{M}(y)=\mu(y)-\sum_{x} \sum_{\theta} \mathcal{M}(x, y, \theta)
\end{aligned}
$$

The quantity $\mathcal{M}(x, y, \theta)$ is determined in the following way. Consider two consecutive periods, $t$ and $t+1$, and recall the timing of events described above: At the beginning of period, $t$ types are updated and meetings and decisions take place. The number of couples with index $\left(x^{\prime}, y^{\prime}, \theta^{\prime}\right)$ at the beginning of $t+1$ (or equivalently at the end of $t$ ) is recursively given by

$$
\begin{aligned}
\mathcal{M}_{t+1}\left(x^{\prime}, y^{\prime}, \theta^{\prime}\right)= & \sum_{x} \sum_{y} \sum_{\theta} \mathcal{M}_{t}(x, y, \theta) q\left(x^{\prime} \mid x\right) p\left(y^{\prime} \mid y\right) r\left(\theta^{\prime} \mid \theta\right)\left(1-\delta_{M}\right) \\
& \times\left(1-\delta_{F}\right) I_{F t}^{m}\left(x^{\prime}, y^{\prime}, \theta^{\prime}\right) I_{M t}^{m}\left(x^{\prime}, y^{\prime}, \theta^{\prime}\right)+u_{F t}\left(x^{\prime}\right) \phi_{t}\left(y^{\prime}\right) \pi\left(\theta^{\prime}\right) \\
& \times I_{F t}^{s}\left(x^{\prime}, y^{\prime}, \theta^{\prime}\right) I_{M t}^{s}\left(x^{\prime}, y^{\prime}, \theta^{\prime}\right)
\end{aligned}
$$

In words, (14) states that the quantity of couples indexed by $\left(x^{\prime}, y^{\prime}, \theta^{\prime}\right)$ at the beginning of $t+1$ is equal to the quantity of existing couples at the beginning of $t$ whose types and match qualities changed to $\left(x^{\prime}, y^{\prime}, \theta^{\prime}\right)$, whose spouses did not die, and who decided to remain married, plus the number of new couples with index $\left(x^{\prime}, y^{\prime}, \theta^{\prime}\right)$ that formed in period $t$. Therefore, in steady state it must be true that for every $\left(x^{\prime}, y^{\prime}, \theta^{\prime}\right)$

$$
\begin{aligned}
\mathcal{M}\left(x^{\prime}, y^{\prime}, \theta^{\prime}\right)= & \sum_{x} \sum_{y} \sum_{\theta} \mathcal{M}(x, y, \theta) q\left(x^{\prime} \mid x\right) p\left(y^{\prime} \mid y\right) r\left(\theta^{\prime} \mid \theta\right)\left(1-\delta_{M}\right) \\
& \times\left(1-\delta_{F}\right) I_{F}^{m}\left(x^{\prime}, y^{\prime}, \theta^{\prime}\right) I_{M}^{m}\left(x^{\prime}, y^{\prime}, \theta^{\prime}\right)+u_{F}\left(x^{\prime}\right) \phi\left(y^{\prime}\right) \pi\left(\theta^{\prime}\right) \\
& \times I_{F}^{s}\left(x^{\prime}, y^{\prime}, \theta^{\prime}\right) I_{M}^{s}\left(x^{\prime}, y^{\prime}, \theta^{\prime}\right)
\end{aligned}
$$

This system of equations together with (12) and (13) determine the steady state measures of couples and single agents. In the Appendix, we show that this way of deriving the steady state of the model is equivalent to the condition that the flows in and out of the pool of single or married agents for every possible index $(x, y, \theta)$ are equal in every period.

3.6. Summary: Definition of a Matching Equilibrium. We are now ready to provide a suitable definition of equilibrium for our environment.

Definition. A matching equilibrium consists of a profile of marriage market decision functions $\left(I_{F}^{s}, I_{M}^{s}, I_{F}^{m}, I_{M}^{m}\right)$, a profile of labor decision functions $\left(l_{F}^{s}, l_{M}^{s}, l_{F}^{m}\right.$, $\left.l_{M}^{m}, l_{F}^{w}, l_{M}^{w}\right)$, government expenditure $G$, a tax system $\left(T^{m}, T^{s}\right)$, and marriage and single measures $\mathcal{M}, u_{F}, u_{M}$, such that:

(1) Optimality: Given the meeting probability distributions $\psi$ and $\phi$ induced by $\mathcal{M}$, $u_{F}, u_{M}$, then $\left(I_{F}^{s}, I_{M}^{s}, I_{F}^{m}, I_{M}^{m}\right)$ and $\left(l_{F}^{s}, l_{M}^{s}, l_{F}^{m}, l_{M}^{m}, l_{F}^{w}, l_{M}^{w}\right)$ solve problems (1)-(9).

(2) Marriage market clearing: Given $\left(I_{F}^{s}, I_{M}^{s}, I_{F}^{m}, I_{M}^{m}\right)$ and $\left(l_{F}^{s}, l_{M}^{s}, l_{F}^{m}, l_{M}^{m}, l_{F}^{w}, l_{M}^{w}\right)$, then $\mathcal{M}, u_{F}, u_{M}$ satisfy (12), (13), and (15).

(3) The government's budget is balanced: 


$$
\begin{aligned}
G= & \sum_{x} \sum_{y} \sum_{\theta} \mathcal{M}(x, y, \theta) T^{m}\left(y l_{M}^{m}, x l_{F}^{m}\right) \\
& +\sum_{x} u_{F}(x) T^{s}\left(x l_{F}^{s}\right)+\sum_{y} u_{M}(y) T^{s}\left(y l_{M}^{s}\right)
\end{aligned}
$$

\section{CALIBRATION}

4.1. Functional Forms and Parameters' Choices. We set the model period equal to 1 year. Based on this choice, the parameters and functional forms are selected as follows:

Wages: We assume that the stochastic processes wages of men and women follow are, respectively,

$$
\begin{aligned}
& \log y_{t}=\log k_{M}+\log \tilde{y}_{t} \\
& \log x_{t}=\log k_{F}+\log \tilde{x}_{t}
\end{aligned}
$$

where the parameters $k_{M}$ and $k_{F}$ are constant over time; $\log \tilde{y}_{t}$ and $\log \tilde{x}_{t}$ follow a first-order autoregressive process, with common autoregressive component $\rho$ and independent and normally distributed innovations with mean 0 and variance $\sigma_{\epsilon}^{2}$. Notice that individuals' wages at $t$ are given by $y_{t}=k_{M} \tilde{y}_{t}$ and $x_{t}=k_{F} \tilde{x}_{t}$.

In order to calibrate the parameters of the processes, we proceed as follows. First, given our assumption of a common process for $\log \tilde{x}_{t}$ and $\log \tilde{y}_{t}$, we use the estimates of $\rho$ and $\sigma_{\epsilon}^{2}$ that were obtained by French (2000). This author estimated an autoregressive process for log-wages from a PSID sample, and he reports point estimates of $\rho=0.977$ and $\sigma_{\epsilon}^{2}=0.0141$. The values of the remaining parameters, $k_{M}$ and $k_{F}$, are calculated so that they match the data on average earnings of males and females. We set $k_{M}=1.0$ and look for values of $k_{F}$ such that, in equilibrium, our economy reproduces the overall population ratio between male and female mean earnings. The average of this ratio for the period 1990-1998 is 0.67 (U.S. Bureau of Census, 1999, Historical Income Tables, Table P-39; individuals considered are Full-Time, Year-Round Workers). For computational purposes, we discretize the wage process described above in the following way: Wages take 25 possible values, evenly spaced in the $\log$ scale, ranging from $-4 \tilde{\sigma}$ to $4 \tilde{\sigma}$, where $\tilde{\sigma}^{2}=\sigma_{\tilde{y}}^{2}=\sigma_{\tilde{x}}^{2}$ is the stationary variance of the common stochastic process for $\log \tilde{y}_{t}$ and $\log \tilde{x}_{t}$.

Match quality: We assume that the shock that affects the quality of the match takes two values, namely $\theta_{L}$ and $\theta_{H}, \theta_{H}>\theta_{L}=0$. This choice implies that in the case of a realization of $\theta_{L}$, household income after taxes is a pure public good. The transition function for shocks is assumed to be symmetric, with $r\left(\theta_{L}, \theta_{L}\right)=$ $r\left(\theta_{H}, \theta_{H}\right)=\bar{r}$; thus, its stationary distribution is simply $\pi\left(\theta_{L}\right)=\pi\left(\theta_{H}\right)=1 / 2$. Consequently, we are left with two parameters to pin down, $\theta_{H}$ and $\bar{r}$. We search across values of these parameters (in conjunction with $k_{F}$ ) so that, in equilibrium, the benchmark economy matches two statistics of the U.S. marriage market, namely the mean duration of marriages ending in divorce and the correlation of spouses' labor earnings as a measure of assortative mating by income. 
We target a mean duration of marriage equal to 9.8 years, which was the value estimated for the United States in 1990 (National Center for Health Statistics, Monthly Vital Statistics Report, Vol. 43, 9, Supplement, Table 10). Using PSID data for the period 1988-1993, we calculate a correlation coefficient between the earnings of husbands and wives equal to (approximately) $0.20 .^{8}$ Using CPS data, Cancian and Reed (1999, Fig. 2) also report values for the correlation between the earnings of husbands and wives in the neighborhood of 0.20 for the period 1984-1994. Hence, we take this value as the corresponding target for the benchmark economy.

Preferences: The per-period utility function takes the form

$$
U(c, 1-l)=\frac{\left[c^{\alpha}(1-l)^{1-\alpha}\right]^{(1-\sigma)}}{(1-\sigma)}
$$

The coefficient of consumption in the composite good, $\alpha$, is set equal to 0.33 . ${ }^{9} \mathrm{We}$ also set $\sigma=4.0$; this value is in the range of estimates reviewed by Prescott (1986) and Auerbach and Kotlikoff (1987). Finally, the discount factor $\beta$ is set equal to 0.96 . This choice implies a rate of time preference of approximately 4 percent per year.

Mortality rates: We assume that males and females enter the labor and marriage markets at the age of 20. Using data on life expectancy of individuals at the age of 20 for 1990 (U.S. Bureau of Census, Statistical Abstract of the United States, 1999, Table 128), we obtain $\delta_{F}=0.0167$ and $\delta_{M}=0.0187$.

4.2. Taxes. In order to properly address the questions posed in Sections 1 and 2, we model the following features of the current tax system $\left(T^{s}, T^{m}\right)$ in the United States: (i) The tax system is progressive and married couples pay taxes based upon the combined income of the spouses; (ii) there are different tax schedules for married couples and for singles, with the property that the width of tax brackets for married couples is not equal to twice the width of corresponding brackets for single individuals; (iii) the standard deduction for married agents is not necessarily equal to twice the amount applied to single individuals.

The (gross) income of a married couple is given by

$$
y l_{M}^{m}+x l_{F}^{m}
$$

Incomes for single men and women are denoted by $y l_{M}^{s}$ and $x l_{F}^{s}$, respectively. The taxable income of a married couple is defined as

$$
y l_{M}^{m}+x l_{F}^{m}-d^{m}-2 e
$$

where $d^{m}$ is the standard deduction a married couple is entitled to and $e$ denotes personal exemptions. The taxable incomes of single males and females are given by $y l_{M}^{s}-d^{s}-e$ and $x l_{F}^{s}-d^{s}-e$, respectively. Notice that (i) the combined gross income

\footnotetext{
${ }^{8}$ We consider only couples in which both spouses report positive hours. If we consider couples in which both spouses work more than 1500 hours per year, the correlation increases slightly to 0.216 .

${ }^{9}$ This is the value that is typically used in growth or business cycles models in order to match the fraction of time devoted to market work in steady state. We choose this value since we are are not aware of estimates for this parameter in environments like the one analyzed in this article.
} 
of a married couple is used in the determination of the taxable income and (ii) only the standard deduction is applied in a way that is contingent on marital status.

Taxes are imposed over "brackets" of taxable income. For example, if a couple's taxable income is $y l_{M}^{m}+x l_{F}^{m}-d^{m}-2 e \in\left[a_{j-1}^{m}, a_{j}^{m}\right)$, then the corresponding tax liability is

$$
T^{m}\left(y l_{M}^{m}, x l_{F}^{m}\right)=\tau_{1} a_{1}^{m}+\tau_{2}\left(a_{2}^{m}-a_{1}^{m}\right)+\cdots+\tau_{j}\left(y l_{M}^{m}+x l_{F}^{m}-d^{m}-2 e-a_{j-1}^{m}\right)
$$

where $a_{j}^{m}$ and $\tau_{j}, j=1,2, \ldots, N$ are the married income-tax "bendpoints" and marginal tax rates, respectively, with $a_{0}^{m}=0$. Similarly, the tax burden of a single female with taxable income $x l_{F}^{s}-d^{s}-e \in\left[a_{j-1}^{s}, a_{j}^{s}\right)$ is

$$
T^{s}\left(x l_{F}^{s}\right)=\tau_{1} a_{1}^{s}+\tau_{2}\left(a_{2}^{s}-a_{1}^{s}\right)+\cdots+\tau_{j}\left(x l_{F}^{s}-d^{s}-e-a_{j-1}^{s}\right)
$$

$T^{s}\left(y l_{M}^{s}\right)$ is defined in an analogous way. We take tax revenues in the benchmark economy as our measure of government expenditures; these expenditures are kept constant across the tax-reform experiments conducted below. Henceforth, $G$ is interpreted as the tax revenue generated by income taxation. ${ }^{10}$

We now describe our numerical approximation of the U.S. tax system. Table 2 shows the U.S. tax system in 1994 for singles and for married couples filing jointly.

As we note above, taxable income in the benchmark case is equal to the gross income of an individual or a couple minus corresponding standard deductions and personal exemptions. Thus, in order to calibrate income-tax bendpoints, we need to specify values for personal exemptions and standard deductions; together, they implicitly define a threshold level of income below which no income taxes are paid. In this context, the sum of the married standard deduction plus two personal exemptions was about 26.1 percent of the mean household income in 1994, whereas the sum of the standard deduction for singles plus a personal exemption was about 14.5 percent of mean household income in that year. Therefore, taking as given the tax system described in Table 1 and denoting the mean household income of the benchmark economy by $\mathcal{I}$, we set $a_{1}^{s}=0.145 \mathcal{I}, a_{2}^{s}=0.673 \mathcal{I}, a_{3}^{s}=1.424 \mathcal{I}, a_{4}^{s}=2.815 \mathcal{I}$, and $a_{5}^{s}=5.950 \mathcal{I}$ for the case of single individuals. In a similar fashion, for married individuals we set $a_{1}^{m}=0.261 \mathcal{I}, a_{2}^{m}=1.143 \mathcal{I}, a_{3}^{m}=2.394 \mathcal{I}, a_{4}^{m}=3.512 \mathcal{I}$, and $a_{5}^{m}=$ $6.066 \mathcal{I}$. In both cases, the marginal tax rates are $\tau_{1}=0.0, \tau_{2}=0.15, \tau_{3}=0.28, \tau_{4}=0.31$, $\tau_{5}=0.36$, and $\tau_{6}=0.396$. We summarize our approximation of the U.S. system in Table 3.

4.3. Summary. From the previous discussion, there are three parameters for which we do not use estimates, namely (i) the highest match quality shock $\theta_{H}$, (ii) the match quality persistence parameter $\bar{r}$, and (iii) the parameter $k_{F}$. We target the

\footnotetext{
${ }^{10}$ The reader may wonder why we do not allow married individuals to choose their filing status. The answer is that the tax code is designed to induce married individuals to file taxes as "married filing jointly": married people who file individually face tax brackets with a width equal to one-half the width applied to those who file jointly. Consequently, filing individually when married typically entails a tax penalty. In fact, about 95 percent of U.S. households choose to file taxes as married filing jointly (General Accounting Office, 1996).
} 
TABLE 2

INCOME TAX SCHEDULE (I994) (IN MULTIPLES OF MEAN HOUSEHOLD INCOME)

\begin{tabular}{lcc}
\hline $\begin{array}{l}\text { Marginal } \\
\text { Tax Rate }\end{array}$ & $\begin{array}{c}\text { Taxable Income } \\
\text { (Married, Filing Jointly) }\end{array}$ & $\begin{array}{c}\text { Taxable Income } \\
\text { (Single) }\end{array}$ \\
\hline 0.15 & $0-0.882$ & $0-0.528$ \\
0.28 & $0.882-2.133$ & $0.528-1.279$ \\
0.31 & $2.133-3.251$ & $1.279-2.670$ \\
0.36 & $3.251-5.805$ & $2.670-5.805$ \\
0.396 & $5.805-$ & $5.805-$ \\
\hline
\end{tabular}

TABLE 3

TAX SYSTEM IN BENCHMARK ECONOMY

\begin{tabular}{lcc}
\hline $\begin{array}{l}\text { Marginal } \\
\text { Tax Rate }\end{array}$ & $y l_{M}^{m}+x l_{F}^{m}$ & $y l_{M}^{s}$ or $x l_{F}^{s}$ \\
\hline 0.0 & {$[0,0.261 \mathcal{I})$} & {$[0, .145 \mathcal{I})$} \\
0.15 & {$[0.261 \mathcal{I}, 1.143 \mathcal{I})$} & {$[0.145 \mathcal{I}, 0.673 \mathcal{I})$} \\
0.28 & {$[1.143 \mathcal{I}, 2.394 \mathcal{I})$} & {$[0.673 \mathcal{I}, 1.424 \mathcal{I})$} \\
0.31 & {$[2.394 \mathcal{I}, 3.512 \mathcal{I})$} & {$[1.424 \mathcal{I}, 2.815 \mathcal{I})$} \\
0.36 & {$[3.512 \mathcal{I}, 6.066 \mathcal{I})$} & {$[2.815 \mathcal{I}, 5.950 \mathcal{I})$} \\
0.396 & {$[6.066 \mathcal{I})$,} & {$[5.950 \mathcal{I})$,} \\
\hline
\end{tabular}

following three statistics: (i) the correlation of spouses' earnings; (ii) the mean duration of a marriage ending in divorce; and (iii) the ratio of mean earnings of females and males in the overall population, or sex earnings ratio. In equilibrium, our benchmark economy generates values of these statistics given $\left(\theta_{H}, \bar{r}, k_{F}\right)$. We then search across values of the unknown parameters $\left(\theta_{H}, \bar{r}, k_{F}\right)$ in order to minimize the distance between the model statistics and the empirical values of the targets. This search yields $\theta_{H}=0.337546, \bar{r}=0.989413$ and $k_{F}=0.747769$.

\section{THE BENCHMARK ECONOMY}

Table 4 presents the basic statistics generated by our model. Before conducting numerical experiments, it is important to review the performance of our model in light of available data. As we argue below, our model is successful in reproducing several features of the data pertaining to labor and marriage markets. This is so despite the fact that our model is a parsimonious one, and we only target a few statistics.

The table shows that it is not problematic for the model to match the correlation of spouses' earnings, the sex earnings ratio, and the mean duration of marriages ending in divorce; this is important, for these are the statistics we have chosen to match since they are key for the questions we address. They are intimately related to marriage formation and dissolution, and to the extent to which married couples benefit or not through the tax law.

Although we match the mean duration of marriages, our model also performs reasonably well regarding other duration statistics. Using CPS data, Castro Martin 
TABLE 4

BENCHMARK ECONOMY SUMMARY STATISTICS

\begin{tabular}{lcc}
\hline Statistic & Model & U.S. \\
\hline Marriage duration (years) & 9.77 & 9.8 \\
Earnings correlation & 0.201 & 0.20 \\
Sex earnings ratio & 0.669 & 0.67 \\
Fraction married (\%) & 71.1 & 67.0 \\
Disruption rate (5 years) & 0.32 & $0.23-0.38$ \\
Labor supply elasticities & & \\
$\quad$ Married female (own wage) & 0.583 & $0.2-1.0$ \\
$\quad$ Married male (own wage) & 0.312 & 0 \\
Coeff. variation hours & & $0.23-0.41$ \\
$\quad$ All & 0.152 & $0.18-0.45$ \\
Married women & 0.206 & $0.23-0.33$ \\
$\quad$ Married men & 0.120 & \\
Marriage penalties & & $42-47$ \\
$\quad$ Couples (\%) & 78.4 & 2.0 \\
Size (\%) & 0.94 & \\
Marriage bonuses & & $49-51$ \\
Couples (\%) & & 2.3 \\
Size (\%) & 21.6 & \\
\hline
\end{tabular}

and Bumpass (1989) found that the cumulative rates of marital disruption over 5 years for the cohort of 1980 marriages were 23, 27, and 38 percent for first, second, and third marriages, respectively. Our model implies that approximately 32 percent of unions are dissolved within 5 years. ${ }^{11}$

Regarding labor-supply decisions, our model is qualitatively consistent with the large number of elasticity estimates that can be found in the empirical literature: For instance, the labor supply of married females is significantly more "elastic" than the labor supply of married males, and it displays an important negative association with husbands' wages (the elasticity is -0.613). Quantitatively, it is worth noting that the calculated elasticities of the labor supply of married females with respect to their own wages are within the range of estimates reviewed recently by Blundell and MaCurdy (1999). Our model, however, generates larger labor-supply responses for married males than those that have been estimated empirically. ${ }^{12}$

11 The marital survival probabilities generated by our model are $0.91,0.78,0.68$, and 0.5 for $1,3,5$, and 10 years, respectively.

${ }^{12}$ It is not easy to compare labor-supply elasticities generated by our model with those obtained in the empirical literature. On the one hand, our model abstracts from labor participation decisions and discrete choices of the number of hours worked (e.g., part time, full time, overtime, etc.), as well as childbearing. On the other hand, several empirical papers take marital status as an exogenous variable. The elasticities reported in Table 4 take into account the important fact that marriage and labor market decisions are intertwined, and they also include the role that tax rules play on the joint labor-supply decisions of the spouses. 
In terms of cross-sectional dispersion in the labor supply, our economy generates more volatility in the number of hours worked by married females relative to those worked by married males, a feature that is consistent with the data. Quantitatively, the statistics in Table 4 indicate that our model displays much less volatility in hours worked than the volatility observed. ${ }^{13}$ We view these findings as a desirable outcome of our model, since we abstract from other factors that may generate higher volatility in hours (e.g., life-cycle considerations).

Table 4 also reports statistics related to the distribution of tax penalties and bonuses. ${ }^{14}$ The coexistence of marriage penalties and bonuses of a nontrivial magnitude emerges endogenously in our model for essentially all levels of income. The model, admittedly, underestimates the overall fraction of couples facing tax bonuses. For instance, the Congressional Budget Office (1997, p. 30) reports that about half of all married couples received such tax-induced marital benefits. Given that in the model everyone participates in the labor market, and since a high fraction of couples with tax bonuses in the data are those in which one of the spouses does not participate in the labor force, our results should best be viewed as pertaining to couples in which both spouses work.

\section{REFORMS}

Our general formulation of the tax system allows us to investigate the implications of several tax reforms. In particular, we study the following:

(1) A tax reform that eliminates tax penalties and bonuses associated with the current application of the standard deduction and the width of the tax brackets for single and married individuals. We analyze the implications of setting the standard deduction and the width of tax brackets for married individuals equal to twice the amount applied to singles. More precisely, we take the values of the standard deduction and tax bendpoints for singles used in the benchmark economy and we set $d^{m}=2 d^{s}$ and $a_{j}^{m}=2 a_{j}^{s}, j=1, \ldots, N$. Such a tax system eliminates the sources of tax penalties, but it increases the magnitude of and scope for tax bonuses (recall the example in Section 2). For this reason, we label this reform partial reform.

(2) A tax reform that maintains the progressivity of the current tax code, but with the property that the unit subject to taxation is the individual rather than the household. We leave unchanged the tax schedule of single individuals and set

\footnotetext{
${ }^{13}$ Using PSID data for the period 1988-1993, we calculate coefficients of variation of $0.447,0.328$, and 0.414 for married females, married males, and all individuals, respectively. Only individuals reporting positive hours are considered. If we consider individuals reporting more than 1500 annual hours, the corresponding values are $0.180,0.227$, and 0.226 , respectively.

14 Tax penalties and bonuses are calculated as the difference between the amount of income tax a couple pays and the amount the couple would pay if they were filing as single individuals; formally, if $T^{m}\left(x l_{F}^{m}, y l_{M}^{m}\right)-T^{s}\left(x l_{F}^{m}\right)-T^{s}\left(y l_{M}^{m}\right)>0$ there is a tax penalty, and there is a tax bonus if this expression is negative. The income used to calculate the magnitude of the tax penalties (bonuses) is the mean household income of those married couples facing penalties (bonuses).
} 


$$
T^{m}\left(y l_{M}^{m}, x l_{F}^{m}\right)=T^{s}\left(x l_{F}^{m}\right)+T^{s}\left(y l_{M}^{m}\right)
$$

It is worth mentioning that this tax system does not treat married couples symmetrically (it lacks "equal treatment"), in the sense that now the tax liability of a couple with a given income depends on the amount generated by each spouse. But, as is well known, such a reform achieves marriage neutrality: two individuals have the same tax liability regardless of their marital status. Since the nature of this tax system is substantially different from the current one, we call this case fundamental reform.

(3) A replacement of the current tax code by the following system:

$$
\begin{aligned}
T^{m}\left(y l_{M}^{m}, x l_{F}^{m}\right) & =2 b+\tau\left(y l_{M}^{m}+x l_{F}^{m}\right) \\
T^{s}\left(y l_{M}^{s}\right) & =b+\tau y l_{M}^{s} \\
T^{s}\left(x l_{F}^{s}\right) & =b+\tau x l_{F}^{s}
\end{aligned}
$$

where $b \leq 0$ is effectively a transfer accruing to all individuals and the marginal tax rate $\tau$ is the same for all agents, regardless of their income level or marital status. When $b=0$, (16) becomes a tax system with a flat income-tax rate, whereas if $b<0$, then the system displays progressivity with increasing average tax rates but a constant marginal tax rate. The fact that the marginal tax rate is constant has nontrivial and interesting implications for labor supply at the individual and household levels: Compared to the benchmark case, (16) may increase marginal tax rates for some individuals and/or couples and decrease them for others. As Berliant and Rothstein (2000) demonstrate, a tax system like this can achieve progressivity, marriage neutrality, and equal treatment of married couples. When $b=0$, it also satisfies the property that if an individual has the same income as a married couple, then both have the same tax liability. Since when $b<0$ (16) is effectively a negative income tax system, we label this case negative income-tax reform. When $b=0$, we call it flat income-tax reform.

In order to achieve revenue neutrality in the tax-reform experiments that we conduct, we proceed as follows. In the case of partial and fundamental tax reforms, all individuals pay a flat-rate income tax $\bar{\tau}$ in addition to the general income tax. In each case, we search for the value of $\bar{\tau}$ that generates, along with the general income tax system, the same government revenue as in the benchmark case. In the negative income tax and flat income tax cases, we search for the value of the single tax rate $\tau$ that balances the budget.

For expositional purposes, we divide our set of computational experiments into two parts. In the first part, we explore the implications of the partial and fundamental tax reforms. That is, we study the two hypothetical reforms that preserve the progressivity of the current tax system. In the second part, we present the corresponding results for the flat income tax and negative income tax reforms.

6.1. Partial and Fundamental Tax Reforms. Tables 5-8 summarize the main implications of both the partial and fundamental tax reforms. Our results indicate that these reforms increase the fraction of the population that is married, the 
duration of marriages, and the labor supply of married and single individuals, but especially the labor supply of married females. They have similar negative effects on assortative mating by wages (productivities) in the marriage market, but the positive sorting of individuals by income increases with the fundamental reform and decreases with the partial reform relative to the benchmark case.

In the partial reform, the number of married couples increases by about 1 percent relative to the benchmark economy. Qualitatively, this result is intuitive, for such a reform eliminates all tax-induced marriage penalties but increases the scope for tax bonuses. Thus, it provides further incentives for marriage formation.

A noteworthy finding emerging from Table 5 is the fact that the effects on the number of married couples and the mean duration of marriages are larger under the fundamental reform than in the partial reform case ( 2.4 vs. 1 percent for the number of couples). A priori, this seems peculiar, since by construction the fundamental reform eliminates all tax-induced benefits and penalties on marriage formation. Also, notice that despite the fact that both reforms reduce the correlation between spouses' wages, the partial reform decreases the correlation between spouses' income whereas the opposite happens under the fundamental reform.

The explanation for these results lies in the fact that the two reforms have different effects on labor-supply decisions. In order to gain a better understanding of the interplay of forces present in the model, consider first the case where labor supply is held constant. When we move from the benchmark to the partial reform case, the elimination of tax penalties and the existence of a larger scope for tax bonuses lead to an increase in the set of individuals that an agent finds acceptable as marriage

TABLE 5

FUNDAMENTAL AND PARTIAL TAX REFORMS: BASIC STATISTICS

\begin{tabular}{lccc}
\hline $\begin{array}{l}\text { Model } \\
\text { Statistic }\end{array}$ & $\begin{array}{c}\text { Benchmark } \\
\text { Economy }\end{array}$ & $\begin{array}{c}\text { Partial } \\
\text { Reform }\end{array}$ & $\begin{array}{c}\text { Fundamental } \\
\text { Reform }\end{array}$ \\
\hline $\bar{\tau}(\%)$ & - & 0.85 & 0.17 \\
Income & 100.0 & 100.5 & 101.0 \\
$\quad$ All & 100.0 & 100.8 & 101.3 \\
$\quad$ Married & 100.0 & 99.8 & 100.7 \\
Singles & & & 0.306 \\
Labor hours & 0.303 & 0.304 & 0.304 \\
$\quad$ All & 0.300 & 0.301 & 21.3 \\
$\quad$ Married & & & 18.2 \\
Mean mg. rate (Married) & 21.5 & 20.7 & 72.8 \\
$\quad$ Males & 21.5 & 20.7 & 10.2 \\
Females & 71.1 & 71.8 & \\
Married couples (\%) & 9.8 & 10.0 & 0.289 \\
Marriage duration & & & 0.640 \\
$\quad$ (years) & 0.201 & 0.187 & 0.643 \\
Income corr. & 0.653 & &
\end{tabular}


TABLE 6

MEAN LABOR HOURS

\begin{tabular}{lccc}
\hline $\begin{array}{l}\text { Model } \\
\text { Statistic }\end{array}$ & $\begin{array}{c}\text { Benchmark } \\
\text { Economy }\end{array}$ & $\begin{array}{c}\text { Partial } \\
\text { Reform }\end{array}$ & $\begin{array}{c}\text { Fundamental } \\
\text { Reform }\end{array}$ \\
\hline $\begin{array}{l}\text { Males } \\
\text { Married }\end{array}$ & 0.323 & & 0.324 \\
$\quad$ Single & 0.311 & 0.326 & 0.311 \\
Females & & 0.311 & \\
$\quad$ Married & 0.276 & & 0.284 \\
$\quad$ Single & 0.313 & 0.277 & 0.313 \\
\hline
\end{tabular}

TABLE 7

MEAN LABOR HOURS OF MARRIED FEMALES (BY MARRIED COUPLES' INCOME)

\begin{tabular}{lccc}
\hline $\begin{array}{l}\text { Multiples of Household } \\
\text { Income }\end{array}$ & $\begin{array}{c}\text { Benchmark } \\
\text { Economy }\end{array}$ & $\begin{array}{c}\text { Partial } \\
\text { Reform }\end{array}$ & $\begin{array}{c}\text { Fundamental } \\
\text { Reform }\end{array}$ \\
\hline $0-0.50$ & 0.296 & 0.294 & 0.302 \\
$0.50-1.0$ & 0.294 & 0.292 & 0.289 \\
$1.0-2.0$ & 0.268 & 0.273 & 0.283 \\
$2.0-3.0$ & 0.262 & 0.248 & 0.271 \\
$3.0-4.0$ & 0.236 & 0.246 & 0.249 \\
$4.0-$ & 0.207 & 0.200 & 0.235 \\
\hline
\end{tabular}

TABLE 8

MEAN MARGINAL TAX RATES OF MARRIED FEMALES (BY MARRIED COUPLES' INCOME)

\begin{tabular}{lccc}
\hline $\begin{array}{l}\text { Multiples of Household } \\
\text { Income }\end{array}$ & $\begin{array}{c}\text { Benchmark } \\
\text { Economy }\end{array}$ & $\begin{array}{c}\text { Partial } \\
\text { Reform }\end{array}$ & $\begin{array}{c}\text { Fundamental } \\
\text { Reform }\end{array}$ \\
\hline $0-0.50$ & 14.5 & 14.9 & 11.6 \\
$0.50-1.0$ & 15.0 & 15.8 & 14.9 \\
$1.0-2.0$ & 24.1 & 22.2 & 19.9 \\
$2.0-3.0$ & 29.2 & 29.2 & 24.7 \\
$3.0-4.0$ & 32.5 & 31.8 & 25.5 \\
$4.0-$ & 36.2 & 32.5 & 26.3 \\
\hline
\end{tabular}

partners. This results in an increase in the number of marriages and a decrease in the correlation of spouses' wages. Since in our model there is an inverse relationship between incentives to marriage and incentives to divorce, it follows that marriage duration also increases. If we now allow for labor-supply changes, the existence of additional tax-induced marital benefits provides households with incentives to choose labor hours in such a way that spouses' incomes are far apart. Therefore, one should expect a decrease in the correlation between spouses' incomes.

Now consider the fundamental reform. If labor supply is held constant, then individuals have fewer incentives to accept low-wage partners due to the elimination of tax-induced benefits. This makes agents more selective in their marriage decisions, implying a decrease in the number of marriages and an increase in the correlation of spouses' wages. However, changes in labor supply provide a countervailing effect: 
The marginal tax rate that the second earner of a household faces is lower under the fundamental reform, and this provides agents with incentives to accept low-wage partners and make them participate more actively in the labor market. This effect tends to make agents less selective in the marriage market, and this leads to an increase in the number of marriages, an increase in their duration, a decrease in the correlation of spouses' wages, and an increase in the correlation of their incomes. The results presented in Table 5 suggest that this second effect prevails, and it is strong enough to have a larger impact on the number of marriages than the partial reform.

Tables 6-8 display some features of the distribution of labor hours of married females. Notice that our reasoning above is consistent with the substantial increase of 2.9 percent in the mean number of hours that married females (usually second earners in the model) work under the fundamental reform; the corresponding change in the partial reform case is merely 0.3 percent. Moreover, the effects on market hours of married females tend to become more significant as the income of the couple increases; for example, in couples with incomes between one and two times the mean household income, females increase their labor hours by about 5.6 percent, whereas for couples with income levels greater than four times the mean household income, the increase is in the order of 13.5 percent. These findings are accounted for by the systematic reduction in marginal tax rates on married females induced by the fundamental tax reform, as Table 8 clearly demonstrates.

6.2. Flat and Negative Income Tax Reforms. We now turn to the flat and negative income tax reforms, whose main effects are displayed in Tables 9-11. The value of $b$, the lump-sum transfer accruing to all individuals in the negative income tax system, is set equal to $-0.02 \mathcal{I}$ and $-0.04 \mathcal{I}$, where $\mathcal{I}$ is the mean household income in the benchmark economy.

Tables 9-11 show that both reforms increase the duration of marriages compared to the benchmark case, but the change in the number of marriages is ambiguous; it falls by 0.6 percent with the flat income tax reform and increases as the transfer $b$ increases. Second, although both reforms increase positive sorting by wage and income, the effect is more pronounced in the flat tax reform. Finally, as expected, notice that there are large changes in the hours worked by men and women under both reforms, no matter what the marital status of individuals is. It is interesting to point out that we find again significant effects on mean hours worked of married females and on their distribution; with the exception of $b=-0.04 \mathcal{I}$, the increase in the mean labor supply of married females is larger than the corresponding increase for married males.

In order to understand these results, consider the flat income tax reform and suppose that agents' labor supply is held constant. Compared to the benchmark case, the value of being single increases for individuals with relatively high incomes, whereas this value decreases for agents whose incomes are relatively low, due to the elimination of progressivity in the tax system. Also, notice that for individuals who, on the margin, were willing to accept a low-type partner because of the existence of a tax bonus, the incentives to accept such a partner disappear with the flat income tax reform. Similarly, those individuals who marginally rejected a partner due to the existence of a tax penalty now have incentives to accept him or her. Consequently, it 
TABLE 9

FLAT AND NEGATIVE INCOME-TAX REFORM BASIC STATISTICS

\begin{tabular}{lcccc}
\hline $\begin{array}{l}\text { Model } \\
\text { Statistic }\end{array}$ & $\begin{array}{c}\text { Benchmark } \\
\text { Economy }\end{array}$ & $\begin{array}{c}\text { Flat Income } \\
\text { Tax Reform } \\
(b=0.0)\end{array}$ & $\begin{array}{c}\text { Negative } \\
\text { Income Tax } \\
(b=-0.02 \mathcal{I})\end{array}$ & $\begin{array}{c}\text { Negative } \\
\text { Income Tax } \\
(b=-0.04 \mathcal{I})\end{array}$ \\
\hline $\bar{\tau}(\%)$ & - & 14.2 & 17.4 & 20.9 \\
Income & 100.0 & 108.2 & 105.7 & 103.0 \\
$\quad$ All & 100.0 & 107.6 & 105.2 & 102.3 \\
$\quad$ Married & 100.0 & 111.1 & 107.6 & 103.3 \\
$\quad$ Singles & & & & \\
Labor hours & 0.303 & 0.327 & 0.315 & 0.302 \\
$\quad$ All & 0.300 & 0.323 & 0.313 & 0.301 \\
$\quad$ Married & & & & 20.9 \\
Mean mg. rate (Married) & 21.5 & 14.2 & 17.4 & 20.9 \\
$\quad$ Males & 21.5 & 14.2 & 17.4 & 72.0 \\
Females & 71.1 & 70.7 & 71.0 & 10.3 \\
Married couples (\%) & 9.8 & 9.9 & 10.0 & 0.285 \\
Marriage duration (years) & 0.201 & 0.334 & 0.322 & 0.658 \\
Income corr. & 0.653 & 0.695 & 0.685 & \\
Wage corr. & & & &
\end{tabular}

TABLE 10

MEAN LABOR HOURS

\begin{tabular}{lcccc}
\hline $\begin{array}{l}\text { Model } \\
\text { Statistic }\end{array}$ & $\begin{array}{c}\text { Benchmark } \\
\text { Economy }\end{array}$ & $\begin{array}{c}\text { Tax Reform } \\
\text { Tax }\end{array}$ & $\begin{array}{c}\text { Negative } \\
\text { Income Tax } \\
(b=0.02 \mathcal{I})\end{array}$ & $\begin{array}{c}\text { Negative } \\
\text { Income Tax } \\
(b=0.04 \mathcal{I})\end{array}$ \\
\hline $\begin{array}{l}\text { Males } \\
\text { Married }\end{array}$ & 0.323 & 0.344 & & \\
$\quad$ Single & 0.311 & 0.333 & 0.335 & 0.326 \\
$\begin{array}{l}\text { Females } \\
\text { Married }\end{array}$ & & & 0.324 & 0.313 \\
Single & 0.276 & 0.304 & 0.291 & 0.277 \\
\hline
\end{tabular}

TABLE 11

MEAN LABOR HOURS OF MARRIED FEMALES (BY MARRIED COUPLES' INCOME)

\begin{tabular}{lcccc}
\hline $\begin{array}{l}\text { Multiples of Household } \\
\text { Income }\end{array}$ & $\begin{array}{c}\text { Benchmark } \\
\text { Economy }\end{array}$ & $\begin{array}{c}\text { Flat Income } \\
\text { Tax Reform } \\
(b=0.0)\end{array}$ & $\begin{array}{c}\text { Negative } \\
\text { Income Tax } \\
(b=0.02 \mathcal{I})\end{array}$ & $\begin{array}{c}\text { Negative } \\
\text { Income Tax } \\
(b=0.04 \mathcal{I})\end{array}$ \\
\hline $0-0.50$ & 0.296 & 0.320 & 0.297 & 0.264 \\
$0.50-1.0$ & 0.294 & 0.311 & 0.294 & 0.279 \\
$1.0-2.0$ & 0.268 & 0.300 & 0.290 & 0.278 \\
$2.0-3.0$ & 0.262 & 0.298 & 0.289 & 0.278 \\
$3.0-4.0$ & 0.236 & 0.274 & 0.276 & 0.273 \\
$4.0-$ & 0.207 & 0.256 & 0.260 & 0.249 \\
\hline
\end{tabular}


is unclear whether individuals become more or less selective in their acceptance and continuation decisions. This renders the net impact of the flat tax reform on the number of marriages, duration, and assortative mating by wages undetermined. The results in Table 9 indicate that the forces that prevail are the ones that make agents more selective, and this leads to a decrease in the number of marriages and an increase in positive sorting by wages. Notice that such a feature is not inconsistent with the observed increase in duration of marriages; the reform changes the composition of the marriage pool, which now includes a larger fraction of agents with relatively low types who tend to have lower option values of being single, and, therefore, divorce less frequently.

If we now take labor-supply changes into account, it is easy to see that the elimination of an increasing schedule of marginal tax rates provides agents incentives to work more hours. Furthermore, since the flat income tax reform achieves marriage neutrality, the tax benefits of having spouses with dissimilar incomes are eliminated. Therefore, one should expect an increase in the number of hours worked and also a higher correlation between spouses' incomes. This is precisely what Tables 9-11 illustrate.

Similar forces are present under the negative income tax reform. The only difference is the existence of $b<0$ : This provides agents with incentives to include lower types in their acceptance/continuation sets, making them less selective in the marriage market than they would be in the flat income tax system. Furthermore, $b<0$ reduces the incentives to work in an asymmetric way within a household, and it therefore induces a greater disparity between the incomes of the spouses. Hence, compared to the flat tax reform, we should expect to find an increase in the number of marriages and in their duration, a decrease in wage and income correlation, and a decrease in the number of labor hours supplied to the market. Columns 3 and 4 of Tables 9-11 clearly display these features, and also the fact that they become more pronounced as $b$ increases in magnitude.

Quantitatively, it is worth emphasizing the substantial effects that flat and negative income tax reforms have on the number of labor hours supplied and their distribution by individuals' income and marital status. For instance, mean hours worked increases by 7.9 percent relative to the benchmark economy under the flat income tax reform, and by about 4 and -0.3 percent, respectively, in the negative income tax case. Nevertheless, there is a strong increase in mean income even for $b=-0.04 \mathcal{I}$, which reflects sharp increases in labor hours of agents with high productivity (high income). In this regard, Tables 10 and 11 indicate that there are sizeable changes in the distribution of labor hours by married females. For instance, notice that when $b=-0.04 \mathcal{I}$, mean hours worked of married females increases only slightly relative to the benchmark case; however, we observe a substantial increase in hours worked by females in high-income couples.

\section{DISCUSSION}

Our results indicate that reforms to the tax treatment of married and single individuals have important effects on labor-supply decisions (mainly of married women), assortative mating and, to a lesser extent, the number of marriages and divorces. We have emphasized that these issues must be analyzed considering both 
labor and marriage markets simultaneously, since there are key links between them. That is, any serious attempt to quantify the effects of implementing marriage-tax neutrality should be conducted in a general equilibrium framework that incorporates these two markets.

We now present the results of a series of experiments that are based on "partialequilibrium" versions of our model. These exercises allow us to evaluate and quantify the marginal contribution of some of the features that we have incorporated in our model.

7.1. Exogenous Marriage. In the first experiment, we evaluate the effects of the various reforms under the assumption that the measure of marriages $\mathcal{M}(x, y, \theta)$ is the same as in the benchmark economy. In other words, we neglect the marriage market changes that ensue with the reforms, and focus only on changes in labor supply.

Table 12 demonstrates that compared to the case of our model economy, there are substantial differences in the magnitude of changes in the number of hours worked. For instance, under the fundamental reform, the number of hours worked by married females increases now by 3.6 percent compared to the 2.9 percent found in the previous section. That is, neglecting changes in the marriage market leads to an estimate of the change in labor hours of married females that is about 25 percent higher. Similarly, the change in labor hours worked under a flat income tax is about 15 percent lower when marriage market changes are not taken into account. The intuition of these results comes from the fact that individuals adjust to reforms only via changes in labor supply, without altering their marital status. We conclude that accounting for changes in the composition of the marriage pool is important if we want to properly quantify the variations in labor hours associated with tax reforms.

7.2. One-Sided Search. We now consider the case in which agents behave "myopically" in the following sense: They assume that meeting probabilities and strategies followed by the agents on the other side of the market are invariant with respect to tax reforms. In doing so, we isolate the role played by the fact that search is "two-sided" in our model rather than "one-sided". ${ }^{15}$

Abstracting from two-sided search considerations has significant effects on the change in the number of marriages associated with each tax reform, as Table 13 clearly shows. For example, under the fundamental reform, the increase in marriage stock is visibly overestimated in the one-sided case relative to the two-sided case (5.5 vs. 2.4 percent). Similar patterns are observed in other reforms. The intuition is the following: As we argue in the previous section, the forces that tend to make people less selective in marital choices dominate in the fundamental reform, and this is the explanation for the increase in the number of marriages. However, a myopic agent does not consider the following mitigating effect that arises in our model: As agents in the market get less selective, the search environment becomes less "tight," and this induces an agent to increase his or her acceptance threshold. By ignoring this equilibrium consideration, individuals tend to accept a larger set of agents

\footnotetext{
15 The number of married and single individuals is calculated by inserting the "myopic" decision rules of the agents into Equations (12), (13), and (15).
} 
TABLE 12

EXOGENOUS MARRIAGE

\begin{tabular}{|c|c|c|c|c|c|c|c|}
\hline \multirow{2}{*}{$\begin{array}{l}\text { Model } \\
\text { Statistic }\end{array}$} & \multirow{2}{*}{$\begin{array}{c}\text { Benchmark } \\
\text { Economy }\end{array}$} & \multicolumn{2}{|c|}{ Fundm. Reform } & \multicolumn{2}{|c|}{ Flat Tax } & \multicolumn{2}{|c|}{$(b=-0.04 \mathcal{I})$} \\
\hline & & Equil. & Exog. & Equil. & Exog. & Equil. & Exog. \\
\hline \multicolumn{8}{|l|}{ Labor hours } \\
\hline All & 0.303 & 0.306 & 0.307 & 0.327 & 0.326 & 0.302 & 0.303 \\
\hline Married & 0.300 & 0.304 & 0.305 & 0.323 & 0.323 & 0.301 & 0.301 \\
\hline Married males & 0.323 & 0.324 & 0.324 & 0.344 & 0.346 & 0.326 & 0.325 \\
\hline Married females & 0.276 & 0.284 & 0.286 & 0.304 & 0.300 & 0.277 & 0.277 \\
\hline Income corr. & 0.201 & 0.289 & 0.306 & 0.334 & 0.267 & 0.285 & 0.278 \\
\hline
\end{tabular}

TABLE 13

ONE- VERSUS TWO-SIDED SEARCH

\begin{tabular}{|c|c|c|c|c|c|c|c|}
\hline \multirow{2}{*}{$\begin{array}{l}\text { Model } \\
\text { Statistic }\end{array}$} & \multirow{2}{*}{$\begin{array}{c}\text { Benchmark } \\
\text { Economy }\end{array}$} & \multicolumn{2}{|c|}{ Fundm. Reform } & \multicolumn{2}{|c|}{ Flat Tax } & \multicolumn{2}{|c|}{$(b=-0.04 \mathcal{I})$} \\
\hline & & Equil. & Myopia & Equil. & Myopia & Equil. & Myopia \\
\hline Marr. stock (\%) & 71.1 & 72.8 & 75.0 & 70.7 & 0.694 & 72.0 & 74.1 \\
\hline Income corr. & 0.201 & 0.289 & 0.269 & 0.334 & 0.340 & 0.285 & 0.288 \\
\hline Wage corr. & 0.653 & 0.640 & 0.625 & 0.695 & 0.698 & 0.658 & 0.658 \\
\hline
\end{tabular}

TABLE 14

EXOGENOUS LABOR DECISION RULES

\begin{tabular}{|c|c|c|c|c|c|c|c|}
\hline \multirow{2}{*}{$\begin{array}{l}\text { Model } \\
\text { Statistic }\end{array}$} & \multirow{2}{*}{$\begin{array}{l}\text { Benchmark } \\
\text { Economy }\end{array}$} & \multicolumn{2}{|c|}{ Fundm. Reform } & \multicolumn{2}{|c|}{ Flat Tax } & \multicolumn{2}{|c|}{$(b=-0.04 \mathcal{I})$} \\
\hline & & Equil. & Exog. & Equil. & Exog. & Equil. & Exog. \\
\hline Marr. stock (\%) & 71.1 & 72.8 & 70.5 & 70.7 & 71.5 & 72.0 & 72.3 \\
\hline Income corr. & 0.201 & 0.289 & 0.216 & 0.334 & 0.261 & 0.285 & 0.205 \\
\hline Wage corr. & 0.653 & 0.640 & 0.664 & 0.695 & 0.691 & 0.658 & 0.657 \\
\hline
\end{tabular}

than they would in the "two-sided" case, and therefore the number of marriages increases; this also accounts for the increase in the degree of assortative mating. Similar explanations apply to the other reforms.

7.3. Fixed Labor Supply. In order to isolate the effects that adjustments in labor supply have on marriage market changes, we now assume that, after a reform, the number of labor hours remains fixed at benchmark economy levels.

Table 14 reports the main findings. Notice the substantial changes in results, both qualitatively and quantitatively. For example, under the fundamental reform, the stock of marriages decreases by about 1 percent compared to the 2.4 percent increase under flexible labor supply; similarly, the correlation between spouses' wages increases instead of decreasing, and the corresponding change in income correlation is substantially underestimated. This can be rationalized as follows: The key force 
that induces agents to become less selective under the fundamental reform is that they can accept less-productive partners and make them work more intensively under the new tax scheme. Obviously, this effect disappears when their labor supply cannot be changed. Thus, agents become more selective and the number of marriages decreases, whereas the degree of assortative mating in terms of wages increases. Similar reasoning applies to the other reforms.

\section{CONCLUDING REMARKS}

In this article, we develop a search theoretic model of marriage formation and dissolution with heterogeneous agents and labor-supply decisions. We calibrate the model and conduct quantitative experiments in order to study the effects of potential reforms of the current U.S. tax system, characterized by differential treatment of married and single individuals. Our results indicate that reforms can have important effects on the number of married couples, on the degree of assortative mating, and, most importantly, on the labor-supply decisions of married females.

We close the article with a short discussion of related issues and model features that we have not considered, and that would be worth looking into further. First, given the way in which we modeled households, agents almost always participate in the labor market and, as a result, we have not dealt explicitly with labor market participation decisions. A promising extension of the model would be to include household production as an alternative to market work; this would provide a better match with existing data in terms of the size of tax-induced marital bonuses. Our conjecture is that the effects of the fundamental reform on labor hours of married females would be larger in this case.

Second, we have not taken into account fertility decisions and childbearing. Again, the inclusion of these features would contribute to a better match with existing data in terms of the number of married couples receiving tax bonuses. Explicit consideration of fertility decisions could also shed light on the potential effects of differential tax treatment of married and single individuals on family size.

Finally, we have abstracted from cohabitation as an alternative to marriage. ${ }^{16}$ Despite the fact that evidence in the United States suggests that the cohabitation experience is short-lived and thus fundamentally different from marriage, it may prove fruitful to incorporate this feature in future analyses of marriage and taxation.

\section{APPENDIX}

A.1. Steady-State Conditions. In this section, we show that the characterization of the measures of singles and married couples given by Equations (12), (13), and (15) is equivalent to the requirement that the number of couples with index $\left(x^{\prime}, y^{\prime}, \theta^{\prime}\right)$ that is destroyed must be equal to the number of couples with this index that is created in each period.

\footnotetext{
16 See Da Vanzo and Rahman (1993) and Bumpass and Sweet (1989) for estimates on the incidence and duration of cohabitation and its role in the formation of married couples.
} 
Notice that (15) can be rewritten as:

$$
\begin{aligned}
\mathcal{M}\left(x^{\prime}, y^{\prime}, \theta^{\prime}\right)= & \sum_{(x, y, \theta) \neq\left(x^{\prime}, y^{\prime}, \theta^{\prime}\right)} \mathcal{M}(x, y, \theta) q\left(x^{\prime} \mid x\right) p\left(y^{\prime} \mid y\right) r\left(\theta^{\prime} \mid \theta\right)\left(1-\delta_{M}\right) \\
& \times\left(1-\delta_{F}\right) I_{F}^{m}\left(x^{\prime}, y^{\prime}, \theta^{\prime}\right) I_{M}^{m}\left(x^{\prime}, y^{\prime}, \theta^{\prime}\right)+\mathcal{M}\left(x^{\prime}, y^{\prime}, \theta^{\prime}\right) q\left(x^{\prime} \mid x^{\prime}\right) \\
& \times p\left(y^{\prime} \mid y^{\prime}\right) r\left(\theta^{\prime} \mid \theta^{\prime}\right)\left(1-\delta_{M}\right)\left(1-\delta_{F}\right) I_{F}^{m}\left(x^{\prime}, y^{\prime}, \theta^{\prime}\right) I_{M}^{m}\left(x^{\prime}, y^{\prime}, \theta^{\prime}\right) \\
& +u_{F}\left(x^{\prime}\right) \phi\left(y^{\prime}\right) \pi\left(\theta^{\prime}\right) I_{F}^{s}\left(x^{\prime}, y^{\prime}, \theta^{\prime}\right) I_{M}^{s}\left(x^{\prime}, y^{\prime}, \theta^{\prime}\right)
\end{aligned}
$$

Adding and subtracting $\mathcal{M}\left(x^{\prime}, y^{\prime}, \theta^{\prime}\right)$ on the right-hand side gives

$$
\begin{aligned}
\mathcal{M}\left(x^{\prime}, y^{\prime}, \theta^{\prime}\right)= & \sum_{(x, y, \theta) \neq\left(x^{\prime}, y^{\prime}, \theta^{\prime}\right)} \mathcal{M}(x, y, \theta) q\left(x^{\prime} \mid x\right) p\left(y^{\prime} \mid y\right) r\left(\theta^{\prime} \mid \theta\right)\left(1-\delta_{M}\right) \\
& \times\left(1-\delta_{F}\right) I_{F}^{m}\left(x^{\prime}, y^{\prime}, \theta^{\prime}\right) I_{M}^{m}\left(x^{\prime}, y^{\prime}, \theta^{\prime}\right)+\mathcal{M}\left(x^{\prime}, y^{\prime}, \theta^{\prime}\right) q\left(x^{\prime} \mid x^{\prime}\right) \\
& \times p\left(y^{\prime} \mid y^{\prime}\right) r\left(\theta^{\prime} \mid \theta^{\prime}\right)\left(1-\delta_{M}\right)\left(1-\delta_{F}\right) I_{F}^{m}\left(x^{\prime}, y^{\prime}, \theta^{\prime}\right) I_{M}^{m}\left(x^{\prime}, y^{\prime}, \theta^{\prime}\right) \\
& +u_{F}\left(x^{\prime}\right) \phi\left(y^{\prime}\right) \pi\left(\theta^{\prime}\right) I_{F}^{s}\left(x^{\prime}, y^{\prime}, \theta^{\prime}\right) I_{M}^{s}\left(x^{\prime}, y^{\prime}, \theta^{\prime}\right)+\mathcal{M}\left(x^{\prime}, y^{\prime}, \theta^{\prime}\right) \\
& -\mathcal{M}\left(x^{\prime}, y^{\prime}, \theta^{\prime}\right) \sum_{x} \sum_{y} \sum_{\theta} q\left(x \mid x^{\prime}\right) p\left(y \mid y^{\prime}\right) r\left(\theta \mid \theta^{\prime}\right)
\end{aligned}
$$

where we have used the fact that

$$
\sum_{x} \sum_{y} \sum_{\theta} q\left(x \mid x^{\prime}\right) p\left(y \mid y^{\prime}\right) r\left(\theta \mid \theta^{\prime}\right)=1
$$

Simple manipulation of (A.1) yields

$$
\begin{aligned}
\mathcal{M}\left(x^{\prime}, y^{\prime}, \theta^{\prime}\right)= & \sum_{(x, y, \theta) \neq\left(x^{\prime}, y^{\prime}, \theta^{\prime}\right)} \mathcal{M}(x, y, \theta) q\left(x^{\prime} \mid x\right) p\left(y^{\prime} \mid y\right) r\left(\theta^{\prime} \mid \theta\right)\left(1-\delta_{M}\right) \\
& \times\left(1-\delta_{F}\right) I_{F}^{m}\left(x^{\prime}, y^{\prime}, \theta^{\prime}\right) I_{M}^{m}\left(x^{\prime}, y^{\prime}, \theta^{\prime}\right)+\mathcal{M}\left(x^{\prime}, y^{\prime}, \theta^{\prime}\right) q\left(x^{\prime} \mid x^{\prime}\right) \\
& \times p\left(y^{\prime} \mid y^{\prime}\right) r\left(\theta^{\prime} \mid \theta^{\prime}\right)\left(1-\delta_{M}\right)\left(1-\delta_{F}\right) I_{F}^{m}\left(x^{\prime}, y^{\prime}, \theta^{\prime}\right) I_{M}^{m}\left(x^{\prime}, y^{\prime}, \theta^{\prime}\right) \\
& +u_{F}\left(x^{\prime}\right) \phi\left(y^{\prime}\right) \pi\left(\theta^{\prime}\right) I_{F}^{s}\left(x^{\prime}, y^{\prime}, \theta^{\prime}\right) I_{M}^{s}\left(x^{\prime}, y^{\prime}, \theta^{\prime}\right)+\mathcal{M}\left(x^{\prime}, y^{\prime}, \theta^{\prime}\right) \\
& -\mathcal{M}\left(x^{\prime}, y^{\prime}, \theta^{\prime}\right) \sum_{(x, y, \theta) \neq\left(x^{\prime}, y^{\prime}, \theta^{\prime}\right)} q\left(x \mid x^{\prime}\right) p\left(y \mid y^{\prime}\right) r\left(\theta \mid \theta^{\prime}\right) \\
& -\mathcal{M}\left(x^{\prime}, y^{\prime}, \theta^{\prime}\right) q\left(x^{\prime} \mid x^{\prime}\right) p\left(y^{\prime} \mid y^{\prime}\right) r\left(\theta^{\prime} \mid \theta^{\prime}\right) \\
& \times\left[\left(1-\delta_{M}\right)\left(1-\delta_{F}\right)+\left(1-\left(1-\delta_{M}\right)\left(1-\delta_{F}\right)\right)\right]
\end{aligned}
$$

which rearranges to

(A.2)

$$
\begin{aligned}
0=\{ & \sum_{(x, y, \theta) \neq\left(x^{\prime}, y^{\prime}, \theta^{\prime}\right)} \mathcal{M}(x, y, \theta) q\left(x^{\prime} \mid x\right) p\left(y^{\prime} \mid y\right) r\left(\theta^{\prime} \mid \theta\right)\left(1-\delta_{M}\right)\left(1-\delta_{F}\right) \\
& \left.\times I_{F}^{m}\left(x^{\prime}, y^{\prime}, \theta^{\prime}\right) I_{M}^{m}\left(x^{\prime}, y^{\prime}, \theta^{\prime}\right)+u_{F}\left(x^{\prime}\right) \phi\left(y^{\prime}\right) \pi\left(\theta^{\prime}\right) I_{F}^{s}\left(x^{\prime}, y^{\prime}, \theta^{\prime}\right) I_{M}^{s}\left(x^{\prime}, y^{\prime}, \theta^{\prime}\right)\right\} \\
- & \left\{\mathcal { M } ( x ^ { \prime } , y ^ { \prime } , \theta ^ { \prime } ) q ( x ^ { \prime } | x ^ { \prime } ) p ( y ^ { \prime } | y ^ { \prime } ) r ( \theta ^ { \prime } | \theta ^ { \prime } ) \left[\left(1-\delta_{M}\right)\left(1-\delta_{F}\right)\right.\right. \\
& \left.\times\left(1-I_{F}^{m}\left(x^{\prime}, y^{\prime}, \theta^{\prime}\right) I_{M}^{m}\left(x^{\prime}, y^{\prime}, \theta^{\prime}\right)\right)+\left(1-\left(1-\delta_{M}\right)\left(1-\delta_{F}\right)\right)\right]+\mathcal{M}\left(x^{\prime}, y^{\prime}, \theta^{\prime}\right) \\
& \left.\times \sum_{(x, y, \theta) \neq\left(x^{\prime}, y^{\prime}, \theta^{\prime}\right)} q\left(x \mid x^{\prime}\right) p\left(y \mid y^{\prime}\right) r\left(\theta \mid \theta^{\prime}\right)\right\} .
\end{aligned}
$$


Consider the right-hand side of (A.2). The first term in curly brackets is the sum of two terms: (i) the number of couples who had index $(x, y, \theta)$ in the previous period, changed to index $\left(x^{\prime}, y^{\prime}, \theta^{\prime}\right)$ in the current period, survived, and decided to continue to be married; (ii) the number of new couples with index $\left(x^{\prime}, y^{\prime}, \theta^{\prime}\right)$ that met in the marriage market in the current period and decided to form a match. In other words, the sum of (i) and (ii) gives the number of matches with index $\left(x^{\prime}, y^{\prime}, \theta^{\prime}\right)$ created in the current period. Similarly, the second term in curly brackets gives the number of matches with index $\left(x^{\prime}, y^{\prime}, \theta^{\prime}\right)$ destroyed in the current period, and consists of the sum of three terms: (i) the number of couples whose index remained $\left(x^{\prime}, y^{\prime}, \theta^{\prime}\right)$, who survived and decided to split; (ii) the number of couples whose index remained $\left(x^{\prime}, y^{\prime}, \theta^{\prime}\right)$ and in which one or both spouses died; (iii) the number of couples whose type was $\left(x^{\prime}, y^{\prime}, \theta^{\prime}\right)$ in the previous period and evolved into a different index this period.

Hence, (A.2) indicates that for any given $\left(x^{\prime}, y^{\prime}, \theta^{\prime}\right)$ the number of couples created must equal the number of couples destroyed in each period.

A.2. Computational Algorithm. The matching equilibrium in the benchmark economy is computed as follows:

1. Guess a value for the mean household income, $\mathcal{I}$. Use this value to calculate income tax bendpoints $a_{j}^{i}$, for $i=m, s$ and $j=1, \ldots, 5$.

2. Solve household decision problems and derive $g^{s}, g^{w}, g^{m}, f^{s}, f^{w}$ and $f^{m}$. Notice that since these are static problems, they can be solved independently of marriage-market decisions.

3. At iteration $k$, guess a measure of marriages $\mathcal{M}^{k}(x, y, \theta)$ for all $(x, y, \theta) \in$ $X \times Y \times \Theta$.

4. Using this guess, use the equations in the text to calculate meeting probabilities $\psi^{k}(x)$ and $\phi^{k}(y)$.

5. Calculate the decision functions $I_{F}^{s k}, I_{M}^{s k}, I_{F}^{m k}, I_{M}^{s k}$. Do this by guessing value functions $v^{s}, v^{m}, v^{w}, z^{s}, z^{m}$, and $z^{w}$, and then iterate until convergence.

6. Update the measure of marriages. That is,

$$
\begin{aligned}
\mathcal{M}^{k+1}\left(x^{\prime}, y^{\prime}, \theta^{\prime}\right)= & \sum_{x} \sum_{y} \sum_{\theta} \mathcal{M}^{k}(x, y, \theta) q\left(x^{\prime} \mid x\right) p\left(y^{\prime} \mid y\right) r\left(\theta^{\prime} \mid \theta\right)\left(1-\delta_{M}\right) \\
& \times\left(1-\delta_{F}\right) I_{F}^{m k}\left(x^{\prime}, y^{\prime}, \theta^{\prime}\right) I_{M}^{m k}\left(x^{\prime}, y^{\prime}, \theta^{\prime}\right)+u_{F}^{k}\left(x^{\prime}\right) \phi^{k}\left(y^{\prime}\right) \pi\left(\theta^{\prime}\right) \\
& \times I_{F}^{s k}\left(x^{\prime}, y^{\prime}, \theta^{\prime}\right) I_{M}^{s k}\left(x^{\prime}, y^{\prime}, \theta^{\prime}\right)
\end{aligned}
$$

for $k=0,1,2, \ldots$ If $\mathcal{M}^{k+1} \sim \mathcal{M}^{k}$, then move to the next step. Otherwise, use the updated measure of marriages as a new guess, go back to step 3, and iterate until convergence.

7. If the implied value of household income coincides with the value guessed in step 1, stop. Otherwise, update the guess and iterate until convergence.

In any of the reforms studied, using the values of household income and government consumption from the benchmark economy, the iteration step over mean household income is replaced by an iteration over the tax rate that achieves budget balance. 


\section{REFERENCES}

Aiyagari, R., J. Greenwood, and N. Gunner, "On the State of the Union," Journal of Political Economy 108 (2000), 213-44.

Alm, J., And L. Whittington, "Income Taxes and the Marriage Decision," Applied Economics 27 (1995a), 25-31.

- AND — , "Does the Income Tax Affect Marital Decisions?," The National Tax Journal 48 (1995b), 565-72.

— AND — , "Income Taxes and the Timing of Marital Decisions," Journal of Public Economics 64 (1997), 219-40.

Auerbach, A., And L. Kotlikoff, Dynamic Fiscal Policy (Cambridge: Cambridge University Press, 1987).

Becker, G., “A Theory of Marriage: Part I,” Journal of Political Economy 81 (1973), 813-46. , “A Theory of Marriage: Part II," Journal of Political Economy 82 (1974), S11-S26.

Berliant, M., And P. Rothstein, "Possibility, Impossibility and History in the Creation of the Marriage Tax," mimeo, Washington University, 2000.

Bloch, F., AND H. Ryder, "Two-Sided Search, Marriages, and Matchmakers," International Economic Review 41 (2000), 93-115.

Blundell, R., And T. MaCurdy, "Labor Supply: A Review of Alternative Approaches," in O. Ashenfelter and D. Card, eds., Handbook of Labor Economics (New York: North Holland, 1999), 1559-1695.

Bumpass, L., AND J. Sweet, “National Estimates of Cohabitation,” Demography 26 (1989), 612-25.

Burdett, K., AND M. Coles, “Marriage and Class,” Quarterly Journal of Economics 112 (1997), 141-68.

_ AND R. Wright, "Two-Sided Search with Nontransferable Utility," Review of Economic Dynamics 1 (1998), 220-45.

CANCIAN, M., AND D. ReED, “The Impact of Wives' Earnings on Income Inequality: Issues and Estimates," Demography 36 (1999), 173-4.

Castro Martin, T., And L. Bumpass, "Recent Trends in Marital Disruption," Demography 26 (1989), 37-51.

Chade, H., "Two-Sided Search and Perfect Segregation with Fixed Search Costs," Mathematical Social Sciences 42 (2001), 31-51.

Congressional Budget Office, "For Better or Worse: Marriage and the Federal Income Tax," CBO Study, Washington, 1997.

Da Vanzo, J., And O. Rahman, “American Families: Trends and Correlates,” Population Index 59 (1993), 350-86.

Feldman, M., And C. Gilles, “An Expository Note on Individual Risk without Aggregate Uncertainty," Journal of Economic Theory 35 (1985), 26-32.

French, E., "The Effects of Health, Wealth and Wages on Labor Supply and Retirement Behavior," mimeo, Federal Reserve Bank of Chicago, 2000.

Greenwood, J., N. Gunner, And J. Knowles, “A Macroeconomic Analysis of Marriage, Fertility and the Distribution of Income," mimeo, Rochester University, 2000.

General Accounting Office, "Income Tax Treatment of Married and Single Individuals," GAO/ GGD-96-175, Washington, 1996.

JUDD, K., "The Law of Large Numbers with a Continuum of IID Random Variables," Journal of Economic Theory 35 (1985), 19-25.

Lu, X., AND P. McAfFEe, "Matching and Expectations in a Market with Heterogeneous Agents," in M. Baye, ed., Advances in Applied Microeconomics (Greenwich, CT: JAI Press, 1996), 121-56.

Morgan, P., "Two-Sided Search and Matching," mimeo, SUNY, 1996.

National Center for Health Statistics, “Monthly Vital Statistics Report," Hyattsville, MD, 1995.

Prescott, E., "Theory Ahead of Business Cycle Measurement," Federal Reserve Bank of Minneapolis Quarterly Review 10 (1986), 9-22.

Regalia, F., And J. V. Rios-Rull, "What Accounts for the Increase in Single Households and the Stability in Fertility?," mimeo, University of Pennsylvania, 1999.

Shimer, R., AND L. Smith, “Assortative Matching and Search,” Econometrica 68 (2000), 343-69. 
Sjoquist, D., And M. Walker, "The Marriage Tax and the Rate and Timing of Marriage," The National Tax Journal 48 (1995), 547-58.

Sмiтh, L. (1997) “The Marriage Model with Search Frictions," mimeo, MIT, 1997.

U.S. Bureau of Census, "Statistical Abstract of the United States," Washington, 1999.

U.S. Bureau of Census, "Current Population Reports," Historical Income Tables, Washington, 1999.

Whittington, L., And J. Alm, "Till Death or Taxes Do Us Apart: Income Taxes and the Divorce Decision," Journal of Human Resources 32 (1996), 388-412. 
